\title{
The Great Balls of Fire: A probabilistic approach to quantify the hazard related to ballistics - a case study at La Fossa volcano, Vulcano Island, Italy
}

\author{
Sebastien Biass ${ }^{\mathrm{a}}$, Jean-Luc Falcone ${ }^{\mathrm{b}}$, Costanza Bonadonna ${ }^{\mathrm{a}}$, Federico Di \\ Traglia $^{\mathrm{c}}$, Marco Pistolesi ${ }^{\mathrm{c}}$, Mauro Rosi ${ }^{\mathrm{d}}$, Pierino Lestuzzi ${ }^{\mathrm{e}}$ \\ ${ }^{a}$ Department of Earth Sciences, University of Geneva, 13, rue des Maraichers, CH-1205 \\ Geneva, Switzerland \\ ${ }^{b}$ Department of Computing Sciences, University of Geneva, CUI, Batelle - Batiment A, \\ 7, route de Drize, CH-1227 Carouge, Switzerland \\ ${ }^{c}$ Earth Sciences Department, University of Florence, Florence, Italy \\ ${ }^{d}$ Italian Civil Protection, Roma, Italy \\ ${ }^{e}$ EPFL, ENAC IIC IMAC, Lausanne, Switzerland
}

\begin{abstract}
Volcanic ballistic projectiles (VBPs) represent a common hazard around volcanoes associated with explosive eruptive styles, and although the number of impact on the ground decreases exponentially with distance from the vent, exposed elements typically present a high vulnerability to VBPs. Recent efforts to assess the hazard related to VBPs have mostly been deterministic, with the final aim being hazard zoning. This approach, suitable when no human settlement is present within a radius of a few kilometres around the vent, is of limited use when urban areas extend close to the active volcanic centre, which requires probabilistic hazard assessments in order to plan and prioritize emergency actions. This is the case at La Fossa volcano, the active crater of the island of Vulcano (Italy), where the activity of the past 1,000 years is characterized by intense ejection of VBPs and where human settlements are located as close as $750 \mathrm{~m}$ from the vent.

To address the need of a probabilistic hazard assessment for VBP impacts, we developed a new numerical model named The Great Balls of Fire $(\mathrm{GBF})$, which describes the ballistic trajectory of particles with variable drag coefficients in a stochastic way and uses a digital elevation model (DEM) to account for topographic barriers. In parallel, a set of associated functions post-processes the output of the model to produce a comprehensive prob-
\end{abstract}


abilistic hazard assessment for VBP impacts. Outcomes include probability maps to exceed given thresholds of kinetic energies at impact, hazard curves and probabilistic isoenergy maps. Probabilities are calculated either on equally-sized pixels or zones of interest.

At La Fossa, the last 1,000 years of activity were characterized by at least 8 long-lasting Vulcanian cycles, each associated with the ejection of VBPs. The GBF model was validated using VBPs produced during the last 1888-1890 eruption that had sufficient stratigraphic constraints to discard reworking, and a generic probabilistic eruption scenario was identified for future Vulcanian eruptions. Results suggest a $10^{-3}-10^{-2} \%$ probability of occurrence of VBP impacts with kinetic energies larger than 4,000 $J$ at the touristic locality of Porto. Additionally, the physical vulnerability of the built environment was assessed from field observations and combined with published literature to identify typical fragility curves for roof perforation. Hazard and vulnerability assessments were then combined to provide a first estimate of the potential impact of VBPs during future Vulcanian eruptions, indicating that for a $50 \%$ probability of occurrence of the hazard, half of the building stock has a $10^{-4}-10^{-3} \%$ probability of roof perforation.

Keywords: Probabilistic hazard assessment, Volcanic ballistic projectiles, Pre-event impact assessment, Physical vulnerability, Roof penetration, Vulcano Island, La Fossa

\section{Introduction}

Volcanic ballistic projectiles (VBP) are angular to sub-angular fragments that decouple from the jet phase of explosive events to follow a near-ballistic trajectory modified by drag forces (Alatorre-Ibargüengoitia et al., 2012). VBPs can be distinguished between blocks, typically of angular shape and lithic origin, and bombs, typically of rounded shape and juvenile origin. These ballistic projectiles can be produced in all types of volcanic eruptions, but are particularly abundant with Vulcanian and Strombolian styles (e.g. Vanderkluysen et al., 2012). Because of their high kinematic energies and temperatures, VBPs constitute a major threat in proximal areas due to their high potential impact to life and the built environment and their propensities to ignite fires. As examples, Pomonis et al. (1999) reports that bombs lighter than $1 \mathrm{~kg}$ are known to have penetrated thatched and galvanized iron roofs during previous eruptions of Furnas volcano (Azores), and Pistolesi et al. 
(2011) and Rosi et al. (2013) reported wildfires triggered by incandescent blocks during the 2007 crisis of Stromboli.

Numerous models for ballistic ejection have been developed since the 1940's to primarily invert field observations and estimate eruptive conditions (e.g. ejection velocity, i.e. Fudali and Melson, 1971; Wilson, 1972; Minakami, 1942; Steinberg and Lorenz, 1983). Although accounting for drag effects, these first models considered the ejection of blocks into a still atmosphere, commonly leading to an overestimation of the atmospheric drag forces and, consequently, unrealistically high ejection velocities. In the context of Vulcanian eruptions, later models considered the presence of a caprock accelerated by the expansion of underlying gas behaving as a coherent plug until a maximum velocity is reached, at which point the fractured caprock disaggregates and individual ballistic blocks are released (Self et al., 1979; Wilson, 1980; Fagents and Wilson, 1993). This disaggregation height has been recently suggested to occur when the acceleration is $8 \%$ of the initial acceleration of the caprock (Alatorre-Ibargüengoitia et al., 2012). This implies a region of reduced drag in the vicinity of the eruptive source, within which the air will itself be moving radially from the source at a velocity comparable to that of the clasts (Fagents and Wilson, 1993). Using this concept, the effect of drag becomes important only when the velocity of the clast gradually decouples from that of the surrounding air, which allows to reproduce observed deposits with significantly lower ejection velocities. The Eject! model of Mastin (2001) is the most widely used model for hazard zonation, and allows to assess the maximum distance that a block of a given size and density can reach for given sets of eruptive conditions (e.g. ejection speed and angle), and accounts for a region of reduced drag defined as an arbitrary distance above the vent and a variation of drag from ejection to landing. De' Michieli Vitturi et al. (2010) proposed a coupled Eulerian-Lagrangian model to describe the dynamics of large particles during Vulcanian eruptions, providing a detailed parametrization of the complex radial and vertical acceleration and deceleration patterns of the initial jet phase. Alatorre-Ibargüengoitia et al. (2012) presented a model coupling lab measurement of the effect of shape on the drag of volcanic particles and a caprock model relating the energy consumption required by fragmentation to the ejection velocity of ballistics (AlatorreIbargüengoitia and Delgado-Granados, 2006; Alatorre-Ibargüengoitia et al., 2010). Recently, Tsunematsu et al. (2014) developed a new approach accounting for multiple particles and collision between blocks.

The aim of hazard assessments is to quantify the probability of occurrence 
of a hazardous phenomenon of a given magnitude (Fournier d'Albe, 1979; Mendoza-Rosas and la Cruz-Reyna, 2008). In volcanology, where eruptions constitute a multi-hazard system, this process is commonly achieved by i) the field characterization of the deposits in order to constrain and quantify Eruption Source Parameters (ESPs), ii) the compilation of a catalogue of eruptions and phenomena at a given volcano to infer eruption scenarios and iii) the forward modelling of a given phenomenon using appropriate models (e.g. Biass et al., 2014). Recent hazard assessments in all fields of natural hazards increasingly rely upon probabilistic techniques in order to account for the inherent uncertainty of natural processes (e.g. Geist and Parsons, 2006; Gonzalez et al., 2009; Heneka and Hofherr, 2011). In volcanology, stochastic strategies have been widely applied to the modelling of tephra (e.g. Bonadonna, 2006; Jenkins et al., 2012) and, more recently, lava flows (e.g. Connor et al., 2012). Probabilistic hazard assessments typically require the identification of eruption scenarios, characterized by typical ranges of ESPs. Each ESP is defined as a probability distribution, constrained by minimum and maximum values as well as a distribution shape. Hazard assessments for ballistics are, however, often based on a deterministic definition of eruption scenarios aiming at producing hazard zones for different block size, ejection angle and initial velocities (Sandri et al., 2014; Alatorre-Ibargüengoitia et al., 2006, 2012). Recently, Fitzgerald et al. (2014) proposed a new probabilistic approach based on the model of Tsunematsu et al. (2014), in which crucial ESPs were quantified in terms of mean value and standard deviation from the field study of 3587 impact craters.

We propose here a new approach to assess the hazard and the impact on the built environment related to the ejection of ballistic blocks, compiled as a package called Great Balls of Fire (GBF; Lewis \& Hammer, 1957, Sun Studio). The first part of the GBF package comprises a model written in Scala, with the main features being i) the stochastic sampling of ESPs, ii) the implementation of a variable drag coefficient, iii) the ability to use a DEM to account for topographic barriers and iv) the possibility to work on a single CPU or on a cluster of computers. The second part of the package provides Matlab routines to post-process the output of the model in order to compute the geographical probability to be affected by VBP impacts of a given energy threshold, and allows to easily export the results into GIS platforms. This paper first describes the ballistic model, which is then tested and validated using field measurements of VBPs produced during the last Vulcanian eruption of La Fossa Volcano, Vulcano Island, Italy. We then compiled an 
eruption scenario for a Vulcanian activity and applied the method to compile probabilistic hazard maps for the ejection of ballistics at La Fossa. Outcomes are combined with a rapid assessment of the built environment to produce a first-order pre-event impact assessment of the buildings stock.

\section{Case study of Vulcano Island}

Vulcano is the southernmost islands of the Aeolian archipelago and, along with Lipari and Stromboli, one of the active volcanic systems of the archipelago (De Astis et al., 1997; Gioncada et al., 2003, Fig. 1). The sub-aerial activity of Vulcano started between 135 and 120 ka years ago (Zanella et al., 2001), after which volcanism migrated towards $\mathrm{N}-\mathrm{NW}$ through time, generating a composite structure characterized by four, juxtaposed volcanic edifices including the cone of La Fossa, center of the current activity (Keller, 1980; Frazzetta et al., 1983; De Astis et al., 1997, 2013; Gioncada et al., 2003). The eruptive history and structure of the $391 \mathrm{~m}$-high La Fossa cone was mostly studied by Arrighi et al. (2006), De Astis et al. (2013), Dellino et al. (2011), Di Traglia et al. (2013), Frazzetta et al. (1984), Frazzetta et al. (1983) and Keller (1980).

The eruptive history of the last 1,000 years was reconstructed based on stratigraphic studies (De Astis et al., 2013; Di Traglia, 2011) and historical chronicles (De Fiore, 1922; Mercalli and Silvestri, 1891). Following the nomenclature of Di Traglia et al. (2013), the most recent deposits were grouped in two stratigraphic clusters including the Palizzi-Commenda Eruptive Cluster (PCEC) and the Gran Cratere Eruptive Cluster (GCEC).

The PCEC is itself divided in two sub-units, including the Palizzi and the Commenda units. The Palizzi unit is characterized by both explosive and effusive styles interrupted by periods of major erosion and re-sedimentation of the newly deposited material (Frazzetta et al., 1984, 1983; Di Traglia, 2011; Dellino and La Volpe, 1997; Dellino et al., 2011; De Astis et al., 2013). The Palizzi unit started with a long-lasting emission of mafic ash followed by a first rhyolitic sub-Plinian eruption (PAL B; Di Traglia et al., 2013). After a period of quiescence occurred a second long-lasting activity of ash emission and a new sub-Plinian phase of trachitic composition (PAL D; Di Traglia et al., 2013), followed by the effusion of two lava flows. The Commenda unit is a magmatic-hydrothermal eruption (Gurioli et al., 2012) comprising the Breccia di Commenda deposit ( 1240AD), characterized by fallouts with a high lithic to juvenile ratio and anomalously large amounts of S and metals 
and the ejection of dense lithic VBPs (Di Traglia et al., 2013; Gurioli et al., 2012).

The GCEC (1440AD-1890AD; Di Traglia et al., 2013) started with a steam-blast eruption on the $5^{\text {th }}$ of February 1444 (Mercalli and Silvestri, 1891), and around 1550AD occurred the first of the eight Vulcanian eruptions of the GCEC (Di Traglia et al., 2013). The last eruption occurred in 1888-1890 and was characterized by plume heights between 1 and $10 \mathrm{~km}$. An intense ejection of VBPs was reported throughout the $\sim 2$ year-long cycle, which produced different morphologies throughout the eruption, with dense lithic blocks occurring at the beginning and the end of the cycle and juvenile bread-crust bombs ejected mostly at the half of the eruption (Bianchi, 2007; Di Traglia, 2011). Outcrops with VBPs associated with the 1888-1890 eruption are shown in Figure 1 (S1-S3). In addition, historical reports also mention that a warehouse located close to the so-called Stevenson Castle (pink star on Fig. 1) was impacted by a VBP.

About 800 people permanently live on Vulcano, but daily peaks can reach 20'000 during the summer season. Four settlements are present on the island. In the south, Piano lies on top of the filled caldera of Vulcano Primordiale and is the home of most of the permanent inhabitant. The remaining settlements of the Porto area, Vulcanello and Lentia comprise most of the hotels and tourism facilities. The topography (Fig. 1) suggests that Piano and Lentia are sheltered by barriers, whereas the Porto and Vulcanello areas lie on a plain directly North of the La Fossa cone.

\section{The GBF Model}

The GBF model is based on classical movement equations using gravity and drag force. The model, described below, accounts for a standard atmosphere, the influence of the wind and a region of reduced drag following Mastin (2001). The bomb simulator was implemented using the Scala language and parallelized with the Akka actor framework. User interactions are provided through a minimalist command line interface and all simulation settings are defined in a simple and human readable configuration file.

\subsection{Governing equations}

Each particle is approximated by a sphere and described by a mass $m$, an average diameter $D$, a position $\mathbf{r}$ and a velocity $\mathbf{v}$. The VBP trajectory is described by the following equations: 


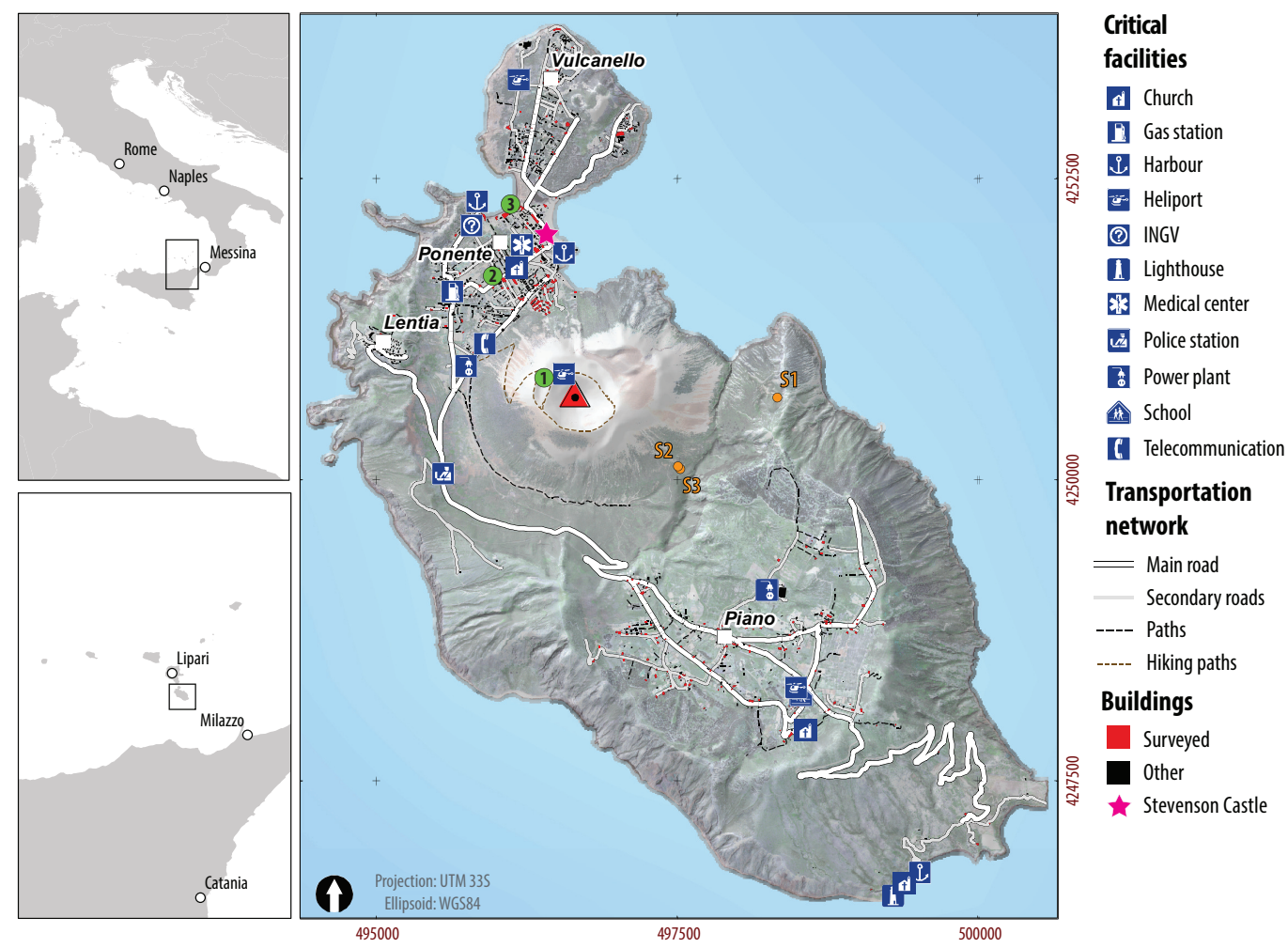

Figure 1: Overview of Vulcano Island, showing the road network, the location of critical infrastructures and the buildings footprints. Green dots show the reference points used for the sensitivity analysis. Orange dots show the field location of the sampling sites. Adapted from Biass et al. (submitted).

$$
\begin{gathered}
\mathbf{u}=\mathbf{v}-\mathbf{w} \\
\ddot{\mathbf{r}}=\dot{\mathbf{v}}=\mathbf{a}=\frac{-\rho_{a} A C_{d} \mathbf{u}|\mathbf{u}|}{2 m}+\mathbf{g}
\end{gathered}
$$

where $A$ is the fluid cross area, $C_{d}$ the drag coefficient, $\rho_{a}$ the air density, $\mathbf{u}$ the velocity of the VBP relatively to the wind $\mathbf{w}$ and $\mathbf{g}$ the acceleration gravity vector. The computation of the drag coefficient and the air density depends on the bomb altitude and velocity. For a given altitude $z$, the air temperature $T$ and pressure $p$ are computed using the following formulas:

$$
T(z)=T_{0}+\gamma z
$$




$$
p(z)=p_{0}\left(\frac{T(z)}{T_{0}}\right)^{-\frac{g}{R \gamma}}
$$

where $T_{0}$ and $p_{0}$ are respectively the air temperature and pressure at sea level, $\gamma$ is the thermal lapse and $R$ the gas constant. This allows the computation of both the air density and the kinematic viscosity $\nu_{a}$ :

$$
\begin{gathered}
\rho_{a}(z)=\frac{p(z)}{R T(z)} \\
\nu_{a}(z)=\left(\frac{6.70810^{-3}}{T(z)+117}\right) \cdot\left(\frac{T(z)}{273}\right)^{\frac{3}{2}}
\end{gathered}
$$

The particle Reynolds number, based on the air characteristics detailed above and the bomb diameter and speed, is used to determine the drag coefficient $C_{d}$ :

$$
\begin{gathered}
R e=\frac{\rho_{a} u D}{\nu_{a}} \\
C_{d}= \begin{cases}0.1 & \text { if } R e<3 \times 10^{5}, \\
0.5 & \text { else }\end{cases}
\end{gathered}
$$

Since bombs are ejected together with an expanding mass of gas, the drag coefficient may be reduced according to the following equation:

$$
C_{d}^{\prime}= \begin{cases}C_{d}\left(\frac{r}{r_{d}}\right)^{2} & \text { if } r<r_{d} \\ C_{d} & \text { else }\end{cases}
$$

\subsection{Random bomb generation}

In order to produce probabilistic hazard assessments for VBPs based on identified scenarios, the GBF model is implemented with a module for generating bombs with random initial conditions. Each VBP is generated with ESPs sampled stochastically and constrained either on Gaussian or uniform distributions (Table 1). Each VBP is characterized by a diameter and a mass, which, assuming a spherical shape, are used to calculate the mass. Additional tests are performed to ensure that all constraints in Table 1 are satisfied, else all parameters are discarded and re-sampled. 
Table 1: Summary of parameters modelled stochastically in the GBF model. $N(\mu, \sigma)$ represents a normal distribution with average $\mu$ and standard deviation $\sigma . U(a, b)$ represents an uniform distribution with values in the interval $[a, b]$.

\begin{tabular}{lll}
\hline Parameter & Distribution & Constraint \\
\hline Ejection velocity $(v)$ & $v \in N\left(v_{\mu}, v_{\sigma}\right)$ & $v>0$ \\
Ejection angle $(\phi)$ & $\in\left|N\left(\phi_{\mu}, \phi_{\sigma}\right)\right|$ & \\
Ejection azimuth $(\theta)$ & $\in U(0,2 \pi)$ & \\
Density $(d)$ & $\in N\left(d_{\mu}, d_{\sigma}\right)$ & $d>0$ \\
Grain size $(\Phi)$ & $\in N\left(\Phi_{\mu}, \Phi_{\sigma}\right)$ & \\
\hline
\end{tabular}

\subsection{Numerical model and implementation}

Equations 1-9 are solved numerically using Runge-Kutta 4th order with a time step $\Delta t=0.01 \mathrm{~s}$. In the absence of an analytic solution, we tested the accuracy of the output by solving the trajectories of 10000 randomly sampled VBPs with time steps of $0.01 \mathrm{~s}$ and $0.001 \mathrm{~s}$. Using the smaller time step as a reference, we computed the absolute error as the distance between impact points under both conditions. The error was below $1 \mathrm{~m}$ for $99.56 \%$ of the bombs and the maximum recorded error was below $3 \mathrm{~m}$. When normalized by the distance between the impact and the vent, only 9 bombs out of 10,000 had a relative error of more than $0.01 \%$.

\subsection{Validation with field data}

The GBF model was validated using the field observation of six VBPs associated with the 1888-1890 eruption presenting sufficient stratigraphic constraints to discard possible reworking and displacement. The VBPs were classified in three typical morphologies including i) lithic blocks, either fresh or altered, ii) thin rind breadcrust bombs and iii) thick rind breadcrust bombs.

Firstly, the S1 sampling site (Fig. 1; Table 2) represents the thick-rinded breadcrust bomb identified by Bianchi (2007) characterized by a diameter of $25 \mathrm{~cm}$ and a density of $1800 \mathrm{~kg} \mathrm{~m}^{-3}$ located $\sim 1560 \mathrm{~m}$ from the vent. Using the Eject! model to infer initial conditions required to reproduce the observation, Bianchi (2007) identified two end-member scenarios. On one hand, the minimum required initial velocity was assessed using an ejection angle of $45^{\circ}$ from vertical, leading to an ejection velocity of $145 \mathrm{~m} \mathrm{~s}^{-1}$. Based on the observations of Mercalli and Silvestri (1891) on the crater morphology during the 1888-1890 eruption, who describe the crater as surrounded by very steep slopes, an inclination of $15^{\circ}$ from the vertical was also tested to 
represent a more realistic ejection angle, which results in an initial velocity of $350 \mathrm{~m} \mathrm{~s}^{-1}$. Such a velocity is higher than the typical range reported in the literature for Vulcanian explosions (e.g. Alatorre-Ibargüengoitia et al., 2012). Secondly, the $S 2$ sampling site represents a $20 \times 20 m$ area where the populations of different VBPs morphologies were studied. From a total of 111 VBPs found in the area, the S2 sampling site shows a dominance of lithic blocks $(80 \%)$ with minor thin- $(14 \%)$ and thick-rinded $(6 \%)$ breadcrust bombs. The most representative VBP of each morphology was measured in terms of the length of the 3 main orthogonal axes and an equivalent diameter was calculated using the geometric mean (Table 2). Finally, one abnormally large thick-rinded breadcrust bomb was located $40 \mathrm{~m}$ further (sampling site S3) and characterized in a similar way (Table 2).

We used the GBF model to invert these observations to infer the potential range of initial conditions. Sets of simulations of $10^{5}$ particles were performed varying the initial velocity between 100 and $350 \mathrm{~m} \mathrm{~s}^{-1}$ (increment of $25 \mathrm{~m} \mathrm{~s}^{-1}$ ) and the ejection angle between 5 and $45^{\circ}$ from the vertical (increment of $5^{\circ}$ ). The density was also adapted for each VBP morphology and was randomly sampled for each simulated bomb on a Gaussian distribution (Table 2). At each simulation, both initial velocity and ejection angle were allowed a narrow variation characterized by a standard deviation equal to half of the increment. From the results, the mean distance reached by VBPs was calculated for each sets of initial velocity and ejection angle. Figure 2 represents the difference between the distances of the observed VBP and the mean distance obtained by the GBF model as a function of initial velocity and ejection angle. The minimum discrepancy between observed and computed VBPs is given by the 0 line in Figure 2 for radii of reduced drags of $200 \mathrm{~m}$ (black line), $600 \mathrm{~m}$ (blue line) and $1000 \mathrm{~m}$ (red line).

For the S1 sample, both the GBF and Eject! models result in similar minimum conditions, i.e. a velocity of $145 \mathrm{~m} \mathrm{~s}^{-1}$ for an ejection angle of $45^{\circ}$ (Fig. 2). In contrast, the GBF model suggests a velocity of $\sim 225 \mathrm{~m} \mathrm{~s}^{-1}$ for an angle of $15^{\circ}$, which is significantly lower than the $350 \mathrm{~m} \mathrm{~s}^{-1}$ suggested by Bianchi (2007) but more realistic when compared to typical ejection velocities reported for Vulcanian explosions (Alatorre-Ibargüengoitia et al., 2006, 2012). Nevertheless, due to the location of the S1 sample (i.e. on the edge of the Piano caldera, $1.6 \mathrm{~km}$ away from the vent) and the absence of historical report of VBP reaching the Piano caldera, we assume the S1 sample as an extreme case-figure. The $\mathrm{S} 2$ and $\mathrm{S} 3$ samples are well reproduced by the GBF model (Fig. 2), where a sound exit velocity of $150 \mathrm{~m} \mathrm{~s}^{-1}$ typically results in 
Table 2: Summary of observed VBPs associated with the 1888-1890 eruption used for the field validation of the GBF model. The distance represents the euclidean distance from the actual vent. The sample locations are reported on Fig. 1. $B C B$ stands for breadcrust bomb.

\begin{tabular}{|c|c|c|c|c|c|c|}
\hline \multirow[t]{2}{*}{ Sampling site } & \multirow[t]{2}{*}{ Type } & \multirow[t]{2}{*}{ Distance $(m)$} & \multirow[t]{2}{*}{ Axes lengths $(\mathrm{cm})$} & \multirow[t]{2}{*}{ Diameter $(\mathrm{cm})$} & \multicolumn{2}{|c|}{ Density $(\mathrm{kg} \mathrm{m}-3)$} \\
\hline & & & & & Mean & $\sigma$ \\
\hline $\mathrm{S} 1$ & Thick-rinded $\mathrm{BCB}$ & 1560 & - & 25 & 1600 & 200 \\
\hline $\mathrm{S} 2$ & Altered block & 960 & $120 \times 65 \times 40$ & $68^{a}$ & 2500 & 100 \\
\hline $\mathrm{S} 2$ & Fresh block & 960 & $40 \times 35 \times 22$ & $31^{a}$ & 2500 & 100 \\
\hline $\mathrm{S} 2$ & Thin-rinded $\mathrm{BCB}$ & 960 & $47 \times 30 \times 10$ & $24^{a}$ & 800 & 50 \\
\hline $\mathrm{S} 2$ & Thick-rinded BCB & 960 & $35 \times 30 \times 18$ & $27^{a}$ & 1600 & 200 \\
\hline S3 & Thick-rinded BCB & 1000 & $70 \times 50 \times 50$ & $56^{a}$ & 1600 & 200 \\
\hline
\end{tabular}

${ }^{a}$ : Equivalent diameter expressed as the geometric mean of the three orthogonal axes.

ejection angles lower than $15-20^{\circ}$. Two extra points can be observed from Figure 2. Firstly, for a similar equivalent diameter and the same sampling point, thin-rinded breadcrust bombs require higher ejection velocities than thick-rinded breadcrust bombs to reproduce the observations, which is due to the lower kinetic energy of lighter bombs. Secondly, an increased radius of reduced drag has an overall low effect on the model results, although the effect increases when reproducing impacts at larger distances from the vent (e.g. S1) or for lighter VBPs (thin-rinded breadcrust bomb of S2).

\section{Application to La Fossa volcano}

\subsection{Eruptive scenarios}

During the activity of the last 1,000 years at La Fossa, two main eruptive styles were recognized to produce VBPs, including non-juvenile steam blast eruptions (i.e. Commenda unit) and Vulcanian eruptions (Di Traglia et al., 2013; De Astis et al., 2013). Since the eruptive dynamics behind both styles are different, we only consider a Vulcanian-type scenario here.

In probabilistic hazard assessments, ESPs are typically characterized by distributions of values rather than single values fixed deterministically in order to account for various types of uncertainties (e.g. aleatoric and epistemic). Here, we developed a Vulcanian-type scenario built around the reference 1888-1890 eruption. ESPs were constrained based on the detailed study of the blocks and bombs provided by the works of Bianchi (2007) and Tsunematsu (2012) as well as additional fieldwork. During the 1888-1890 eruption, the three types of VBP occurred in different proportions and at different stages of the eruption. Dense juvenile blocks represent $70-90 \%$ of the observed VBPs on the field and are reported to have occurred mainly at 

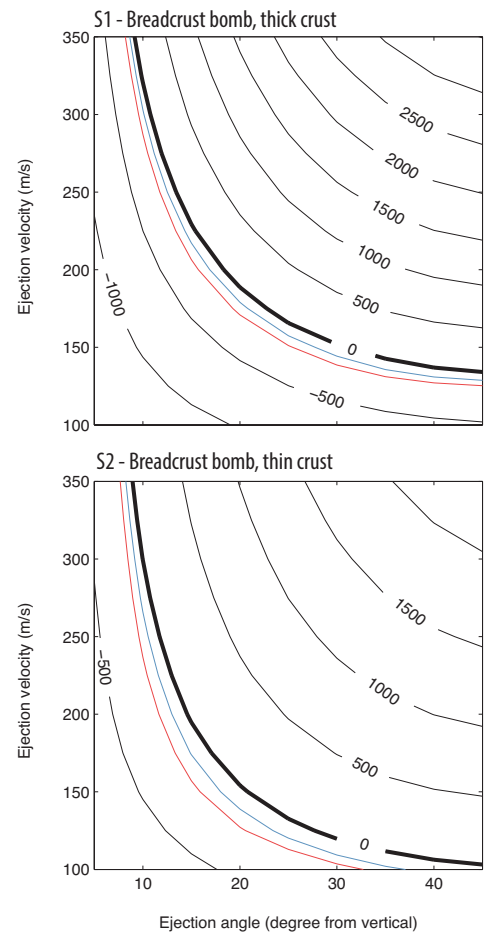

$-R_{\text {Drag }}=200 \mathrm{~m}$

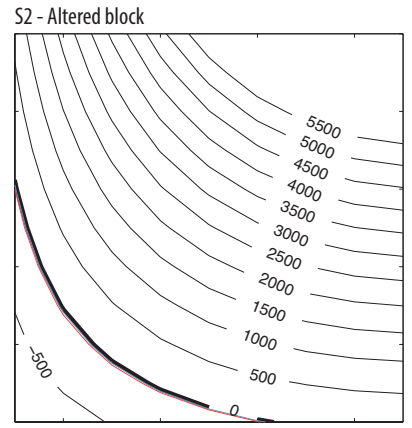

S2-Breadcrust bomb, thick crust

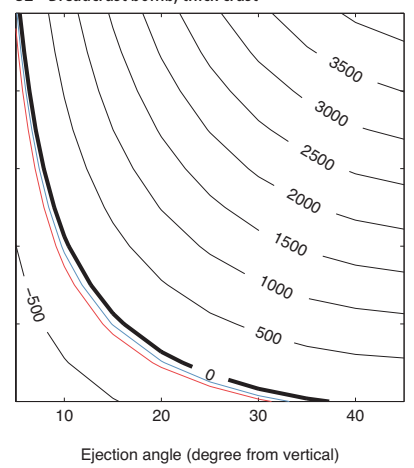

$R_{\text {paga }}=600 \mathrm{~m}$

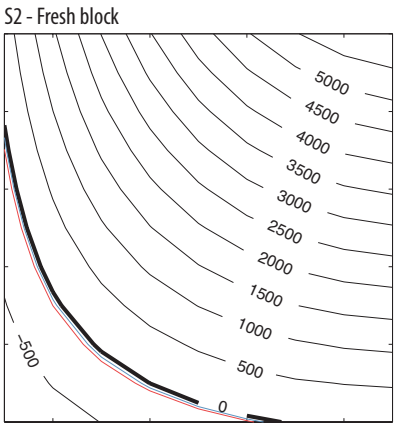

S3 - Breadcrust bomb, thick crust

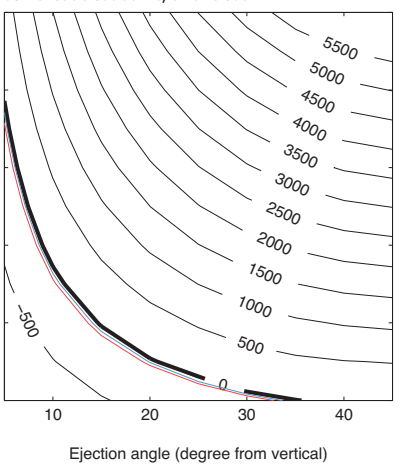

$R_{\text {Drag }}=1000 \mathrm{~m}$

Figure 2: Difference between the distances of the observed VBPs and the mean distance obtained by the GBF model as a function of initial velocity and ejection angle for the various VBP morphologies observed at sampling sites shown in Fig. 1. Various radii of reduced drag are considered and include $200 \mathrm{~m}$ (black lines), $600 \mathrm{~m}$ (blue line) and 1,000 $m$ (red line). The differences in distances are expressed in metres.

the start and the end of the eruption (Mercalli and Silvestri, 1891; Bianchi, 2007; Di Traglia, 2011). Thin-rinded breadcrust bombs represent $5-15 \%$ of the observed VBPs and were produced during the moderate explosions that occurred at the half of the eruption (Mercalli and Silvestri, 1891; Bianchi, 2007; Di Traglia, 2011). Finally, thick-rinded breadcrust bombs are the expression of the most intense explosions that occurred throughout the cycle, and represent 10-20\% of the observed VBPs. Since proportions of each VBP type obtained at the sampling site S2 (Fig. 1; Sect. 3.4) represents a median value compared the reports of previous authors (Mercalli and Silvestri, 1891; Bianchi, 2007; Di Traglia, 2011), we assume a proportion of $80 \%$ of lithic blocks, $14 \%$ of thin-rinded and $6 \%$ of thick-rinded $(6 \%)$ breadcrust bombs. 
Table 3 summarizes the ESPs for the Vulcanian eruption scenario at La Fossa. Variable parameters include i) density $\left(\mathrm{kg} \mathrm{m}^{-3}\right)$, ii) VBP diameter $(\phi)$, iii) ejection velocity $\left(\mathrm{m} \mathrm{s}^{-1}\right)$ and iv) ejection angle (i.e. azimuth, ${ }^{\circ}$ from vertical). The number of observations being too limited to estimate complex probability distributions (e.g. based on Tsunematsu, 2012, $n=12$ for density measurements and $n=40$ for diameter measurements), we used Gaussian distributions centred on the mean value $(\mu)$ and expressing the uncertainty using the standard deviation $(\sigma)$, which accounts for about $68.3 \%$ of the population.

Here, the three types of VBPs are characterized by various ranges of densities, and discontinuities discard the possibility of modelling the density as a continuous range. Instead, separate runs were performed for each VBP type in which i) the density range was adjusted and ii) the number of particles simulated was scaled to reproduce the proportions of each VBP type. The mean densities and associated standard deviations of blocks, thin-rinded and thick-rinded breadcrust bombs were set to $2300 \pm 100,800 \pm 50$ and $1600 \pm 200 \mathrm{~kg} \mathrm{~m}^{-3}$, respectively. The diameter is expressed on a Gaussian distribution in $\phi$ units, which results in a log-normal distribution when converted to metres. The mean diameter considered is $-7.65 \phi$ (i.e. $0.2 \mathrm{~m}$ ) with a $\sigma_{\text {Diam }}=1.2 \phi$. In meters, the $\mu-\sigma$ and $\mu+\sigma$ are 0.09 and $0.46 m$, respectively. The median ejection velocity was set to $100 \mathrm{~m} \mathrm{~s}^{-1}$ with a $\sigma_{V e l}=50 \mathrm{~m} \mathrm{~s}^{-1}$. Although the median velocity is slightly lower than both the theoretical and observed velocities of Alatorre-Ibargüengoitia et al. (2012) for Popocatepetl volcano (Mexico), these authors suggest VBPs reaching maximum distances of 2.6-3.7 km. Based on the inversion modelling presented in Section 3.4 and the reports of Mercalli and Silvestri (1891) and De Fiore (1922), VBPs reaching distances $\geq 1600 \mathrm{~m}$ can be considered as outliers requiring ejection velocities comprised between 120 and $300 \mathrm{~m} \mathrm{~s}^{-1}$ depending on the ejection angle. As a result, values of $\mu_{V e l}$ and $\sigma_{V e l}$ proposed in Table 3 cover well these joint observations. The ejection angle was defined as a mean value centred on the vertical with a standard deviation of $\frac{\pi}{12} \mathrm{rad}$, i.e. $15^{\circ}$.

A case of no wind was used here, and drag forces were accounted for using a standard atmosphere as described by Mastin (2001). A region of reduced drag was set with a radius of $200 \mathrm{~m}$. Alatorre-Ibargüengoitia et al. (2012) report heights of about $600 \mathrm{~m}$ at Popocatepetl volcano, which we chose to reduce since these explosions appear larger and characterized by higher ejection velocities and distances reached by VBPs. It is however important to notice that in the case of La Fossa, an altitude of $200 \mathrm{~m}$ above the vent is 
Table 3: Eruption source parameters associated with a Vulcanian-type eruption scenario at La Fossa volcano based on the eruption of 1888-1890. Different Gaussian distributions of densities are identified for ${ }^{a}$ lithic blocks, ${ }^{b}$ thin-rinded and ${ }^{c}$ thick-rinded breadrcrust bombs.

\begin{tabular}{llcll}
\hline \multirow{6}{*}{ Source } & Unit & Mean & $\sigma$ \\
& Density & $k g m^{-3}$ & 2500 & $100^{a}$ \\
& & & 800 & $50^{b}$ \\
& & & 1600 & $200^{c}$ \\
& Diameter & $\phi$ & -7.65 & 1.2 \\
& Velocity & $\mathrm{ms}^{-1}$ & 100 & 50 \\
& Ejection angle & $r a d$ & 0 & $\pi / 12$ \\
& Number particles & - & $10^{6}$ & - \\
Wind & Speed & $\mathrm{m} \mathrm{s}^{-1}$ & 0 & - \\
& Direction & Degrees & 0 & - \\
& Time step & $\mathrm{s}$ & 0.01 & - \\
& Pressure & $h P a$ & $1.01325 \times 10^{5}$ & - \\
& Temperature at sea level & $\circ \mathrm{K}$ & 298 & - \\
& Thermal lapse & $\circ \mathrm{C} \mathrm{km^{-1 }}$ & $-6.5 \times 10^{-3}$ & - \\
& Reduced Drag radius & $\mathrm{m}$ & 200 & - \\
\hline
\end{tabular}

higher than the surrounding crater.

\subsection{Probabilistic hazard assessment}

The destructiveness caused by VBPs is mostly due to the associated high kinetic energies at the impact, and the aim of this hazard assessment is to investigate the probability to exceed critical energy thresholds. Various thresholds, hereafter expressed as $E_{T}(\mathrm{~J})$, were estimated for the impact on the built environment (e.g. Spence et al., 2005; Pomonis et al., 1999; Jenkins et al., 2014) and will be discussed later. Since VBPs result in discontinuous punctual impacts, it is necessary to average the number of impacts on a representative area. However, since no standardized method yet exists, we explore two different approaches for the quantification of the hazard related to VBPs impacts.

\subsubsection{Pixel-based approach}

As a first approach, we average the VBP impacts on an equally-spaced grid for each pixel of area $A_{i, j}$ in order to quantify the probability of occurrence a VBP of a given energy threshold in a given pixel:

$$
P\left(A_{i, j}, E_{T}\right)=\frac{\sum V B P_{A_{i, j}, E_{T}}}{n_{V B P}},
$$


where $n_{V B P}$ is the total number of simulated VBPs.

Since this approach introduces a dependency on the pixel area, we assess the sensitivity of our post-processing method to i) the number of VBPs simulated and ii) the resolution of the grid used to compile probabilistic hazard assessments. The number of simulated VBPs was varied between $10^{4}$ and $10^{7}$ with increment steps of $10^{1}$. Grid resolutions of 5, 10, 20, 50,75, 100, $200,300,400,500,600,700,800,900$ and $1000 m$ were tested. For each pair of number of particles/grid resolution, 20 simulations were performed, resulting in a total of 1,200 simulations. Probability calculations were performed for three points, namely the top of the hiking path, the center of the Porto area and Porto di Ponente, located at distances from the vent of 400, 1,300 and $1,700 \mathrm{~m}$, respectively (green points 1,2 , and 3 on Fig. 1).

Figure 3 summarizes the sensitivity analysis performed using ESPs in Table 3 and calculating the probability of VBPs exceeding an energy of $4000 \mathrm{~J}$, identified as the minimum energy to penetrate weak RC slabs roofs (Spence et al., 2005). Results show that:

- For a given point, an increase of the number of simulated particles does not significantly affect the mean probability value but greatly reduces the associated standard deviation (Fig. 3);

- For a given number of simulated particles, the probability decreases with distance from the vent but the standard deviation remains in the same order of magnitude;

- For the proximal point (i.e. Point 1 in Fig. 3), a change of order of magnitude of mean probabilities (i.e. $10^{-2 \%}$ to $10^{-1 \%}$ ) occurs at a resolution of about $200 \mathrm{~m}$.

As a result, based on these observations and in order to find a good compromise between computation time and accuracy of the output, we simulate $10^{6}$ particles averaged on a $100 \times 100 \mathrm{~m}$ grid. In the absence of a plateau with stable probability values, we fix the resolution threshold in the zone of the lowest variability of mean probability values.

\subsubsection{Zone-based approach}

As a second approach, we assess the probability of impact in a zone of interest $Z$. Here, such a zone is defined either as a distance from the vent (i.e. the probability of impact at a given distance interval from the vent) or as a 
radial sector (i.e. probability of impact at a given azimuth interval from the vent). Probabilities of a VBP exceeding an energy threshold $E_{T}$ can then be expressed as normalized either on the total number of VBPs simulated or on the number of VBPs that fell in a given zone $Z$. In the first case, $P\left(Z, E_{T}\right)$ answers the question "what is the probability of a VPB to exceed a given energy threshold $E_{T}$ in a zone $Z$ ?". In the second case, $P\left(E_{T} \mid Z\right)$ answers the question "knowing that a VBP impacts the zone $Z$, what is its probability to exceed an energy threshold $E_{T}$ ?".

Note that although the combination of both approaches might result in an overall picture of the VBP hazard around a given volcano, the comparison of the hazard with other volcanoes is difficult due to the nature of both the modelling and the post-processing methods. Additionally, each approach to the probabilistic quantification of the VBP hazard have different purposes. For instance, the zone-based approach is more suitable for hazard zoning purposes, whereas the pixel-based approach is more appropriate for impact assessment purposes. For this reason, this latter one will be discussed in more details in this paper, but the zone-based approach is thoroughly presented in the user-manual of the GBF model.

\subsection{Vulnerability of the built environment}

VBPs can affect the built environment due to the dynamic impact caused by their high kinetic energies, which can result in either damages to the structures, perforation or collapse of the building structure (Pomonis et al., 1999; Blong, 1984; Jenkins et al., 2014; Spence et al., 2005). The propensity of a building to suffer damages is typically expressed through fragility curves, which describe the relationship between the intensity of the hazard and the probability of damage. Such curves must be defined for each hazard and each type of buildings. In the case of tephra fallout, the hazard is expressed as the load caused by fallout leading to failure. For VBPs, the parameter of importance is the kinetic energy at the impact sufficient for roof perforation. Fragility curves are usually defined as a combination of i) empirical compilations of post-eruption observations of damages (e.g. Blong, 2003b; Wilson et al., 2011; Pomonis et al., 1999), ii) laboratory experiments and iii) theoretical studies on material strengths (e.g. Petrazzuoli and Zuccaro, 2004)

Here, we assess the vulnerability of the built environment to roof perforation from VBP impacts. The starting point of this study is the vulnerability curves proposed by Spence et al. (2005) for the European area. Vulnerability 

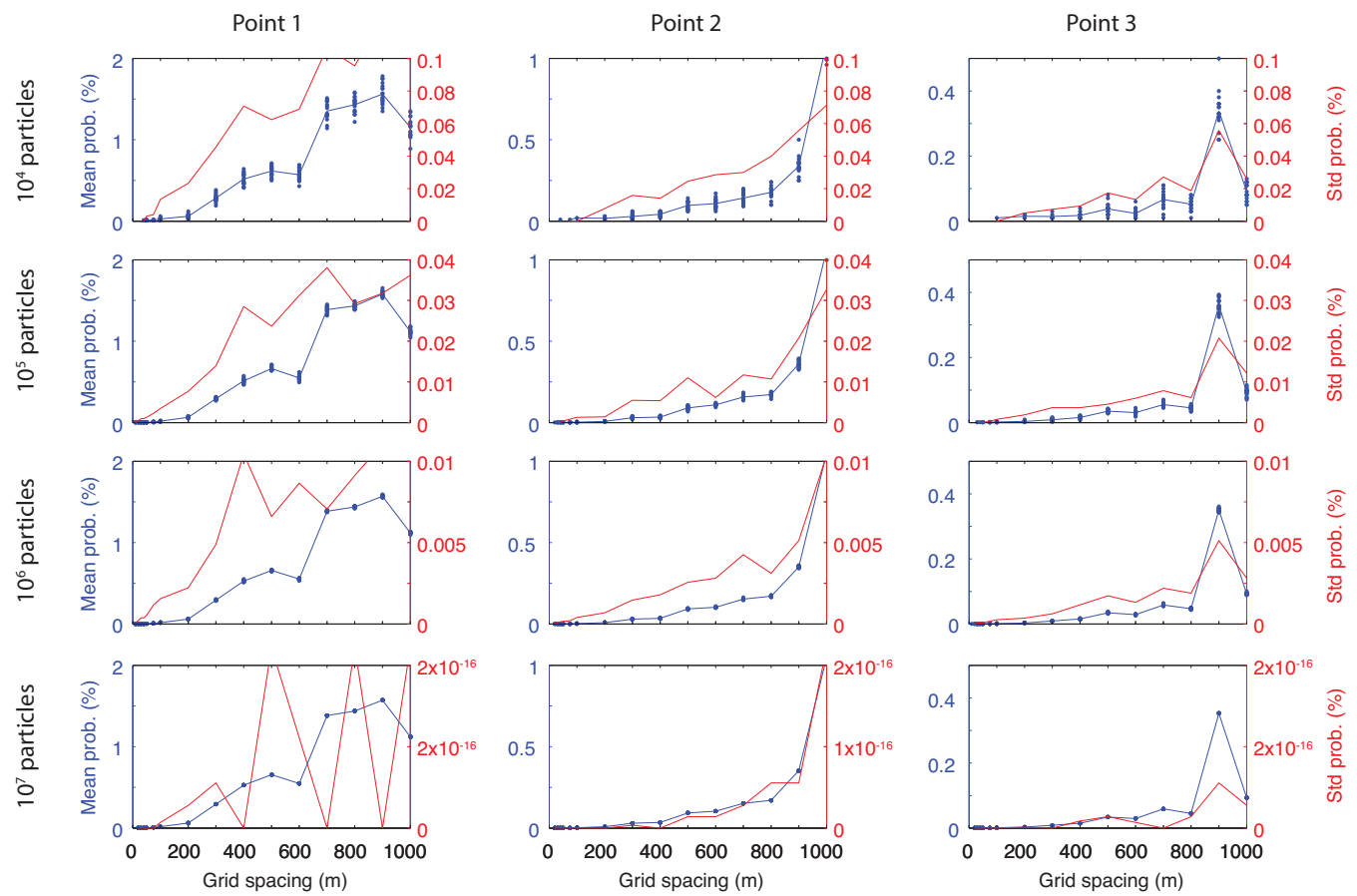

Figure 3: Sensitivity of the probabilistic hazard assessment strategy to i) the number of simulated particles and ii) the resolution of the grid used to quantify the probability of VBPs exceeding a given energy threshold $E_{T}$ of $4000 \mathrm{~J}$. Across sub-plots, the rows represent variable number of simulated particles and the columns represent the different points on which probabilities were calculated and include the top of the hiking path (Point 1), the center of the Porto area (Point 2) and Porto di Ponente (Point 3). Each plot has two y-axes: the left one (blue) shows the mean probability calculated over the 20 simulations (blue dots) for each set of number of particles/grid resolution; the right one (red) shows the corresponding standard deviation.

curves take the shape of a cumulative density function of a normal distribution $(\phi)$ and are expressed as a function of the mean kinetic energy $E_{\text {mean }}$ and a standard deviation $\sigma$ assumed to have a fixed value of 0.2 (Spence et al., 2005). Following Spence et al. (2005) and Jenkins et al. (2014), the probability of perforation $\left(P_{\text {perforation }}\right)$ is expressed as a function of the VBP energy $I(J)$ with the following relationship:

$$
P(\text { Perforation } \mid I)=\phi\left(\ln (I), \ln \left(E_{\text {mean }}\right), \sigma\right)
$$

Biass et al. (submitted) provide a review of the built environment in Vulcano. The 2000 census of the Italian Instituto Nazionale di Statistica 


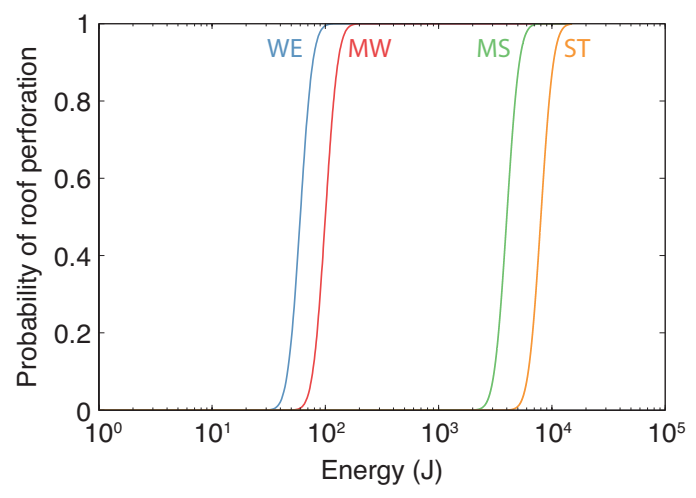

Figure 4: Fragility curves for the roof types $W E, M W, M S$ and $S T$ of Spence et al. (2005) as defined in Table 4.

(ISTAT, 2005) identifies 1093 buildings on the island, comprising 895 residential houses and 64 public and tourism facilities. According to this census, the main construction period spans from the 1970's to 1980's, but discussions with inhabitants and workers on the island suggest that most buildings were renewed over the years, making the true period of construction difficult to assess. Additionally, the field survey realized in the context of the EU-funded ENSURE project (Bonadonna et al., 2011) provides detailed descriptions of the most representative building in a $100 \times 100 \mathrm{~m}$ pixel, revealing that building morphologies are homogeneously distributed over the settled areas and include $70 \%$ single-storey buildings, $73 \%$ with flat roofs and $54 \%$ with a regular morphology. We assume that the majority of flat roofs are composite slabs made of precast reinforced concrete and clay bricks connected by an upper layer of concrete and designed for access, suggesting a resistance to static loads of at least $150 \mathrm{~kg} \mathrm{~m}^{-2}$ (Jenkins et al., 2014). Additionally, our database on the built environment comprises the mapping building's footprints from aerial images (Galderisi et al., 2013).

Spence et al. (2005) identified three typical roofing stocks and their associated probabilities of occurrence over Europe and include Weak, Median and Strong roofing stocks, corresponding to exceedance probabilities of $10 \%, 50 \%$ and $90 \%$, respectively. Each roofing stock is characterized by proportions of four roof types, namely weak (WE), medium weak (MW), medium strong (MS) and strong (ST), each defined by a specific fragility curve. Here, this method is extrapolated for i) the specific case of Vulcano and ii) to consider 
Table 4: Description of the typical roofing stocks of Spence et al. (2005) adapted to the built environment of Vulcano (adjusted from Biass et al. (submitted)). The vulnerability of each roof class is characterized by a mean kinetic energy $E_{\text {mean }}$ and a standard deviation $\sigma$ fixed to 0.2. The $E_{\text {mean }}$ is identified based on existing literature Spence et al. (2005); Tsunematsu (2012); Pomonis et al. (1999); Jenkins et al. (2014); Blong (1984); Mavrouli and Corominas (2010b). The proportions of each roof class in the composite European roofing stocks of Spence et al. (2005) are also shown assuming a median roofing stock $(50 \%$ probability of occurrence) and a strong roofing stock (90\% probability of occurrence). $R C$ stands for reinforced concrete.

\begin{tabular}{|c|c|c|c|c|}
\hline \multirow[t]{2}{*}{ Roof class } & \multirow[t]{2}{*}{ Description } & \multirow[t]{2}{*}{$E_{\text {mean }}(J)$} & \multicolumn{2}{|c|}{$\begin{array}{c}\text { Proportion per } \\
\text { roofing stock }(\%)\end{array}$} \\
\hline & & & Median & Strong \\
\hline WE (weak) & Tiled roof, poor condition & 60 & $34.3 \%$ & $2.7 \%$ \\
\hline MW (medium weak) & Tiled roof, average or good condition & 100 & $44.1 \%$ & $18.9 \%$ \\
\hline MS (medium strong) & Flat $\mathrm{RC}$ roof, average condition & 4000 & $18.9 \%$ & $44.1 \%$ \\
\hline ST (strong) & Flat RC roof, good condition & 8000 & $2.7 \%$ & $34.3 \%$ \\
\hline
\end{tabular}

the impact related to VBPs. Firstly, as described by Biass et al. (submitted) based on the different datasets described above, we assume that the population of buildings in Vulcano are comprised between the typical Median and Strong roofing stocks; the Weak stock is not considered here. Secondly, we assume that buildings either have flat reinforced concrete roofs or tiled roofs over a timber structure, which reflects well the field survey. Note that the majority of buildings described by Biass et al. (submitted) consists of a flat reinforced concrete roof with an additional tiled porch. Finally, the study of Spence et al. (2005) focusing primarily on the impact related to tephra fallout, fragility curves for each typical roof type (i.e. WE, MW, MS or ST) are defined based on critical thresholds of static loads, which we need to extrapolate here to express the vulnerability of the built environment to VBPs.

Table 4 summarizes the roof classification adapted for the built environment on Vulcano, where the quality of both types of observed roofs (i.e. reinforced concrete slabs and tiles) is either in average or good condition. Following equation 11, we translate the approach usually taken to assess the vulnerability to tephra fall to VBPs by defining fragility curves as a cumulative function of a Normal distribution and characterized by a mean energy $E_{\text {mean }}(J)$. Here, $E_{\text {mean }}$ is defined as the ranges published in the existing literature (e.g. Spence et al., 2005; Tsunematsu, 2012; Pomonis et al., 1999; Jenkins et al., 2014; Blong, 1984) for the built environment approximating best the observations on Vulcano. Following the approach applied to 

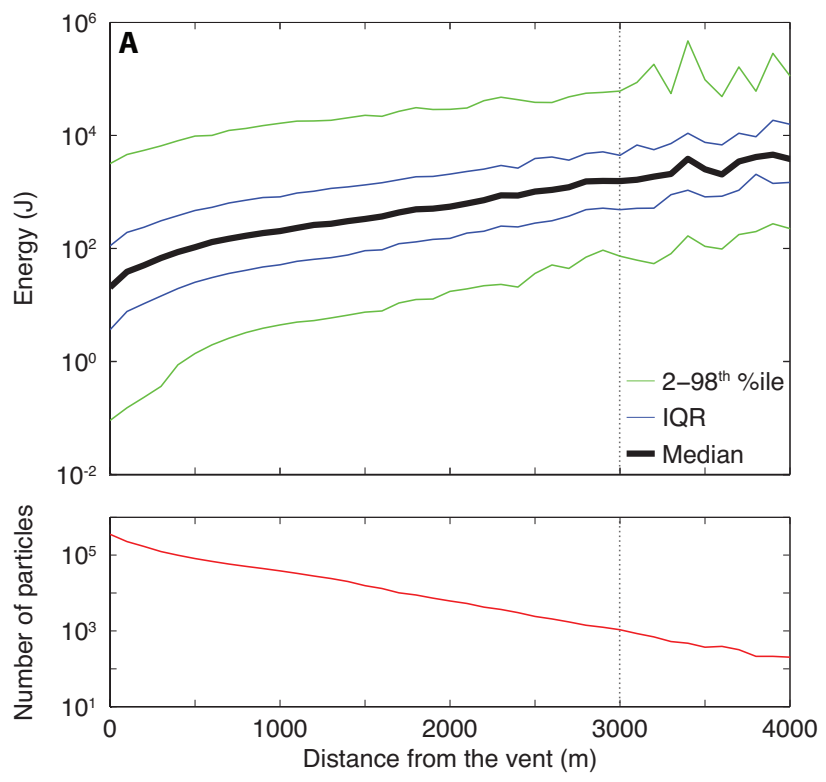

Figure 5: A: Median energy with distance from the vent. The uncertainty is expressed by the $25^{t h}-75^{t h}$ percentiles (i.e. IQR) and the $2^{n d}-98^{t h}$ percentiles. The vertical dashed line indicates the distance (i.e. $\sim 3,000 \mathrm{~m}$ ) at which the number of particles is too limited to produce stable results. B: Number of particles with distance from the vent. A distance of $\sim 3,000 \mathrm{~m}$ corresponds to $\sim 10^{3}$ particles.

tephra fallout, the standard deviation of the distribution $\left(E_{s t d}\right)$ is fixed to 0.2 (Spence et al., 2005; Jenkins et al., 2014).

\section{Results}

For the scenario ran with ESPs defined in Table 3, Figure 5A shows the variation of the median VBP energy with distance from the vent, with the associated variability expressed as the $25^{t h}-75^{t h}$ percentiles (i.e. IQR) and the $2^{\text {nd }}-98^{t h}$ percentiles. Two main observations must be outlined from Figure 5A. Firstly, the median energy increases with distance from the vent, which is a consequence of the caprock assumption used to model Vulcanian explosions (Self et al., 1979; Wilson, 1980; Fagents and Wilson, 1993). Such an assumption implies that once the coherent plug reaches its fragmentation level (here considered as the reduced drag radius in Table 3), all VBPs are released with the same ejection velocity, regardless of their masses. As a result, only large VBPs possess a sufficient kinetic energy to reach distances 
further away from the vent and are therefore associated with relative high impact energies. Secondly, curves in Figure 5A follow a smooth trend up to a distance of $\sim 3,000 \mathrm{~m}$ (i.e. vertical dashed line in Fig. 5), after which the signal becomes chaotic. By projecting this distance on Figure 5B, it can be observed that only $10^{3}$ particles are falling at distances larger than $\sim 3,000 \mathrm{~m}$ (i.e. $0.1 \%$ of the total number of simulated VBPs), which are not sufficient to obtain stable results. Probabilities calculated for distances from the vent larger than $\sim 3,000 m$ should thus be critically used.

\subsection{Hazard assessment}

Following the approach presented in section 4.2, probabilistic maps of VBPs that exceed given hazardous energy thresholds of roof perforation were first compiled. Figure $6 \mathrm{~A}-\mathrm{B}$ shows the geographical distribution of probabilities to exceed impacts of $100 \mathrm{~J}$ (i.e. threshold for the perforation of tiled roofs in average or good condition) and $4000 \mathrm{~J}$ (i.e. threshold for the perforation of reinforce concrete roofs in average condition). Impacts are averaged on a $100 \times 100 m$ pixel and normalized over the total number of simulated VBPs. Figure $6 \mathrm{~A}-\mathrm{B}$ shows an exponential decrease of the probability values with distance from the vent. Secondly, the approach described in section 4.2.1 was applied to estimate probabilities of impact at a given distance from the vent (Fig. $7 \mathrm{~A}-\mathrm{B})$ or at a given radial sector around the vent (Fig. $7 \mathrm{C}-$ D). Probabilities are expressed either as normalized over the total number of simulated VBPs (i.e. $P\left(Z, E_{T}\right)$; Fig. 7A,C) or as normalized over the number of VBPs that impacted the considered zone (i.e. $P\left(E_{T} \mid Z\right)$; Fig. 7B,D). Finally, hazard curves were compiled (Fig. 8), which show the probability of exceeding any impact energy for the settled areas of Porto, Il Piano, Lentia and Vulcanello (white squares in Fig. 1 and Fig. 6), located respectively 1.3, 2.4, 1.8 and $2.6 \mathrm{~km}$ away from the vent.

Results show that Porto, located $1.3 \mathrm{~km}$ North of the vent (Fig 1), is the most exposed settlement with probabilities of impact on tiled and reinforced concrete roofs of $8-9 \times 10^{-3} \%$ and $1-2 \times 10^{-3} \%$, respectively. The second most exposed settlement is Lentia (1.8 $\mathrm{km}$ NE of vent), with probabilities of impact $\sim 3 \times 10^{-3} \%$ (i.e. tiled roofs) and $\sim 5 \times 10^{-4 \%}$ (i.e. reinforced concrete roofs). The settlements of Il Piano and Vulcanello, located at respectively $2.4 \mathrm{~km}$ SW and $2.6 \mathrm{~km} \mathrm{~N}$ of the vent (Fig 1), result in probabilities of $7 \times 10^{-4 \%}$ and $2 \times 10^{-4 \%}$ of impact on tiled roofs, respectively, and negligible probabilities of impact on reinforced concrete roofs. Note that all these probabilities are calculated for a single geographic point in the center of all these settlement 


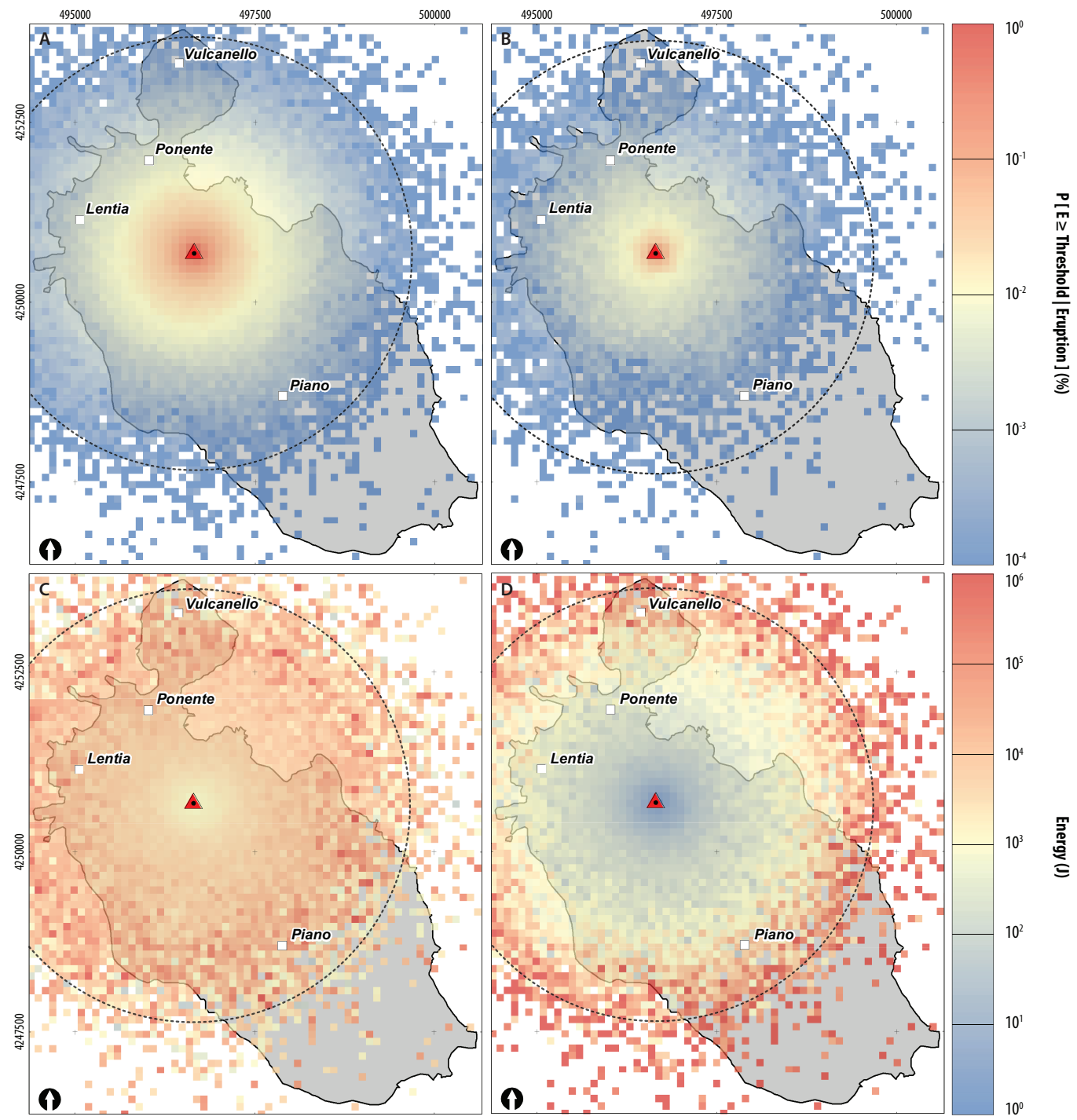

Figure 6: A-B: Probability maps (\%) of VBPs exceeding energies of (A) $100 \mathrm{~J}$ and (B) $4000 \mathrm{~J}$. D-E: Energies for probabilities of occurrence within a given pixel of (D) $10 \%$ and (F) $90 \%$. The towns main are shown as white squares (Fig. 1). The black dashed line contours a distance of $3,000 \mathrm{~m}$ around the vent, considered as the distance beyond which not enough particles are observed to provide stable results (Fig. 5).

and are equal in the $100 \times 100 \mathrm{~m}$ pixel surrounding the respective reference points.

When the zone-based approach is adopted to assess the probability of 
impact at a given distance from the vent (Fig. 7A-B), the choice of the type of probability (i.e. $P\left(Z, E_{T}\right)$ versus $\left.P\left(E_{T} \mid Z\right)\right)$ greatly influences the message carried by the probabilistic hazard assessment. When normalized over the total number of simulated VBPs, Figure $7 \mathrm{~A}$ shows greater probabilities of being impacted by a VPB with a kinetic energy of $4000 \mathrm{~J}$ close to the vent, where a probability of $0.5 \%$ exists up to a distance of $1 \mathrm{~km}$ away from the vent. In contrast, Figure $7 \mathrm{~B}$ shows that should a VBP impact a given zone of interest, there is a larger probability that it will exceed a kinetic energy of $4000 \mathrm{~J}$ at larger distances from the vent. As a result, there is a $25 \%$ probability that a VBP reaching a distance of 3,000 $\mathrm{m}$ from the vent will exceed such an energy threshold. When a similar approach is applied on zones of interest defined as radial sectors around the vent, no notable difference is observed when using either type of probabilities, where $P(Z, 4000 \mathrm{~J})=$ $0.2-0.5 \%$ and $P(4000 J \mid Z)=3-6 \%$ all around the vent. This is possibly due to the absence of any large topographic barrier around the La Fossa cone.

In order to estimate the typical range of VBP energies at a given pixel, maps showing the energy for a given probability of occurrence were also produced (Fig. 6C-D). At each pixel, the $10^{t h}, 25^{t h}, 50^{t h}, 75^{\text {th }}$ and $90^{t h}$ percentiles were calculated over the energy of all VBPs that fell in a given $100 \times 100 m$ area. Since the $n^{\text {th }}$ percentile returns the lowest $n \%$ of the population, there is a $100-n \%$ probability that the energy will exceed the energy given by the $n^{\text {th }}$ percentile. As an illustration, the $10^{\text {th }}$ percentile of a given pixel shows the energy occurring with a $90 \%$ probability within this given pixel. Note that this energy is based upon the conditional probability that a VBP impact is occurring inside this pixel, and does not consider the probability of the pixel to be impacted. Figure $6 \mathrm{C}-\mathrm{D}$ illustrates the geographical distributions of energies for probabilities of occurrence of $10 \%$ and $90 \%$, and reflect the increase of the average energy with distance from the vent observed in Figure 5. Typically, when compared to large probabilities of occurrence, lower probabilities of occurrence result in higher energies close to the vent and lower energies further away. For instance, the crater area is characterized by typical energies of $10^{3} \mathrm{~J}$ and $10^{1} \mathrm{~J}$ for probabilities of occurrence of $10 \%$ and $90 \%$, respectively, by opposition to $10^{4} \mathrm{~J}$ and $10^{3} \mathrm{~J}$ for the Porto area. 

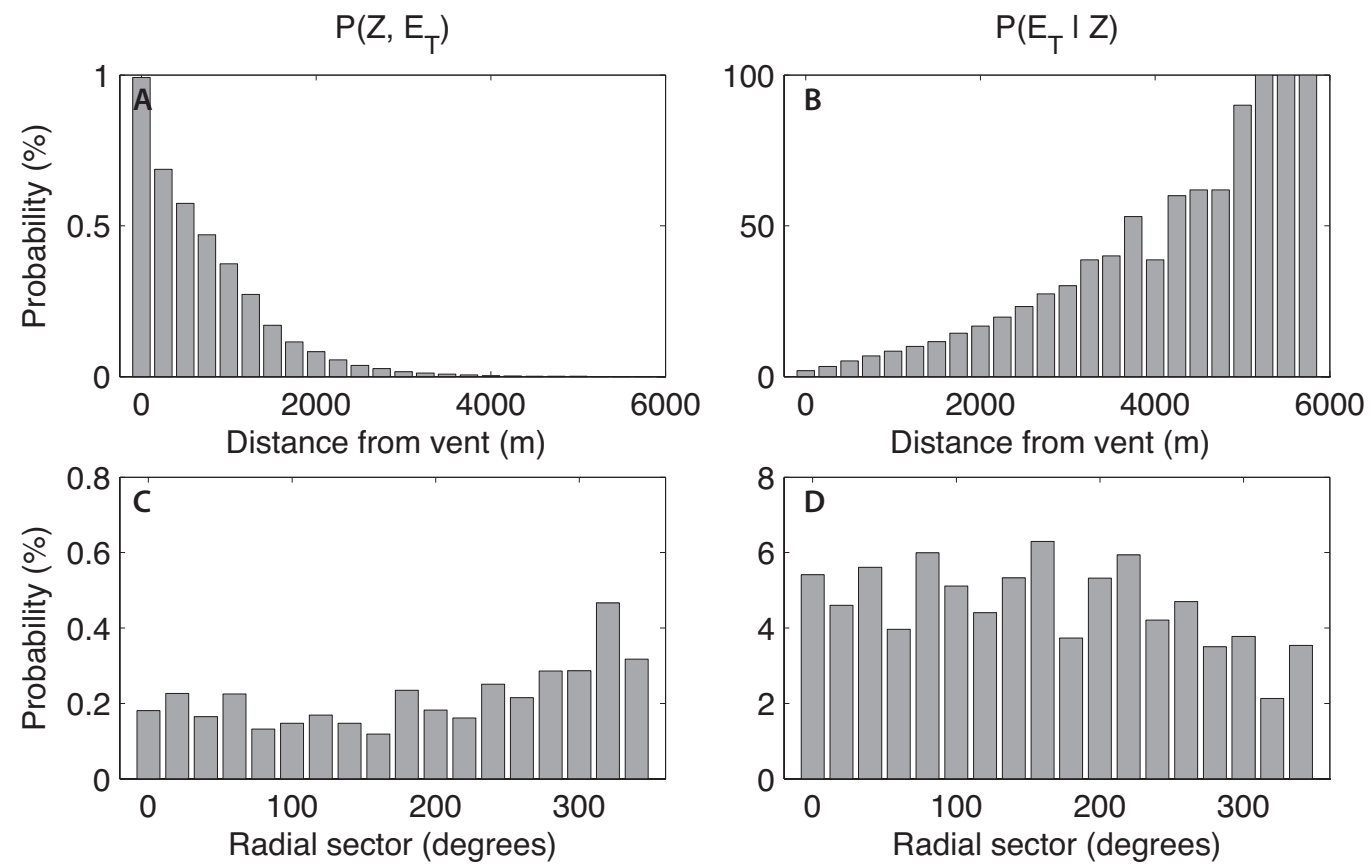

Figure 7: Probabilities of VBPs to exceed a kinetic energy of $4000 J$ at A-B a given distance from the vent and $\mathrm{C}-\mathrm{D}$ a given radial sector around the vent. The left column expresses the probability normalized over the total number of simulated VBPs (i.e. $P\left(Z, E_{T}\right)$ ) whereas the right column is averaged over the number of VBPs that impacted the considered zone (i.e. $P\left(E_{T} \mid Z\right)$ ). Bins sizes are $250 \mathrm{~m}$ for the distance and $20^{\circ}$ for the radial sectors.

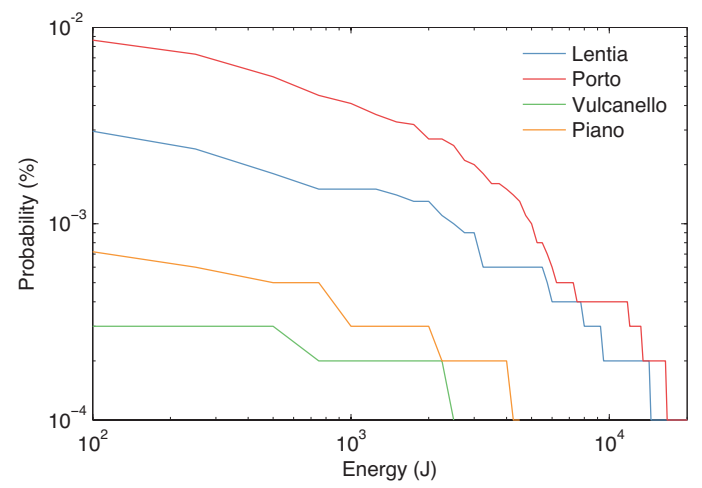

Figure 8: Hazard curves for the urban settlements areas shown as white squares in Fig. 1 and Fig. 6. 


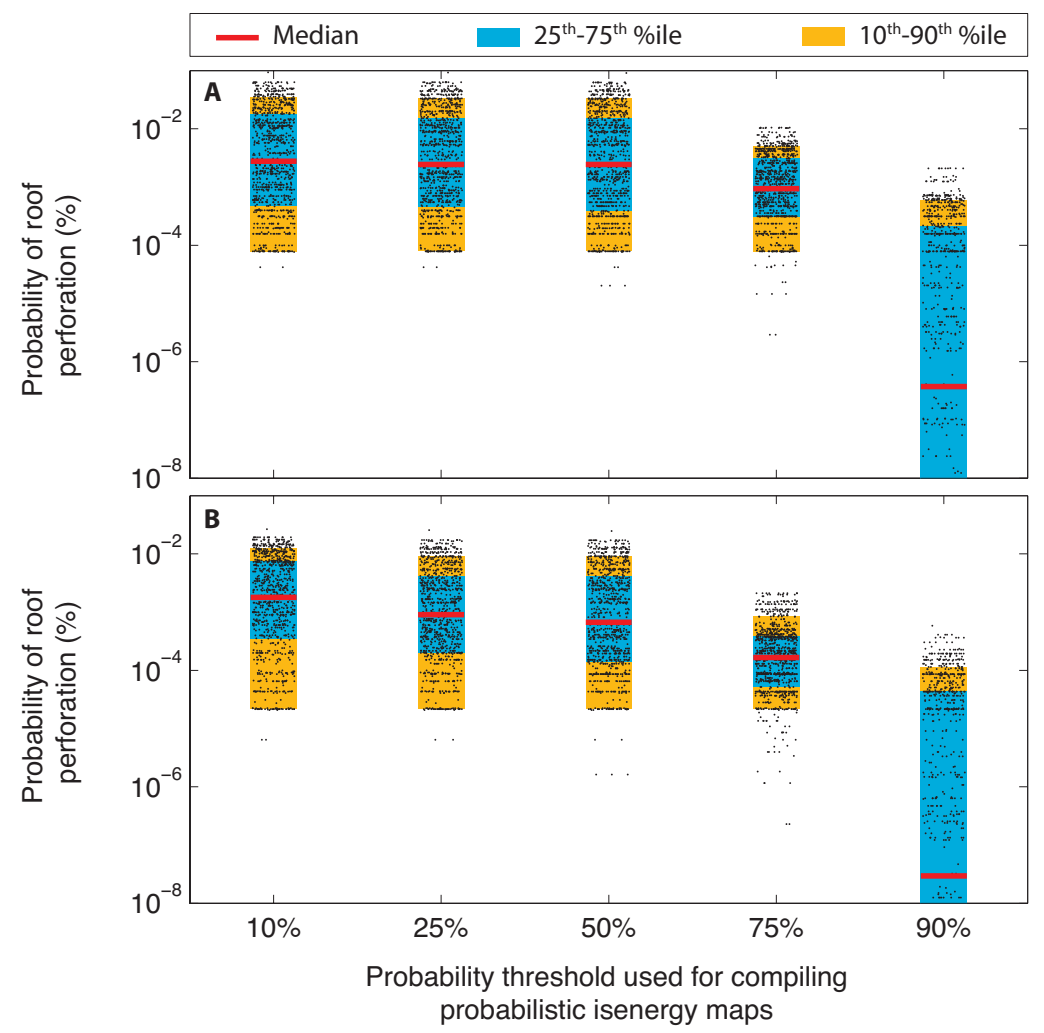

Figure 9: Impact on the built environment considering typical (A) median and (B) strong roofing stocks (Spence et al., 2005). The x-axis shows the probability threshold used to compile probabilistic energy maps. Black dots show the probability of roof collapse of each building resulting from the hazard occurring at a given probability (x axis). Distributions of probabilities of over all buildings are summarized as the median (red line), the $25^{t h}-75^{t h}$ interval (blue box) and the $10^{t h}-90^{t h}$ interval (orange box). For visibility, the lower y axis was manually set to $10^{-8 \%}$.

\subsection{Pre-event impact assessment}

The impact assessment was performed by combining the vulnerability curves shown in Table 4 and Figure 4 with the probabilistic energy maps (Fig. $6 \mathrm{C}-\mathrm{D})$. For each building, energy thresholds of the containing pixel were retrieved for all probabilities of occurrence (i.e. 10\%, 25\%, 50\%,75\% and $90 \%$ ). For each probability threshold, probabilities of roof perforation were calculated for a single building using the four curves defined by Spence et al. (2005) for the $W E, M W, M S$ and $S T$ roof classes (Table 4) and multiplied by the probability of occurrence of VBPs impact within the pixel of interest 
Table 5: Summary of the impact considering a typical Median roofing stock (Spence et al., 2005). Values represent the probability of roof collapse calculated at given percentiles on the distributions shown in Fig. 9. $\mathrm{P}_{\text {thresh }}$ represents the probability threshold used to compile probabilistic energy maps (Fig. 6C-D).

\begin{tabular}{llllll}
\hline \multicolumn{5}{c}{ Probability of roof perforation $(\%)-$ Median roofing stock } \\
\hline Percentile: & $10^{\text {th }}$ & $25^{\text {th }}$ & $50^{\text {th }}$ & $75^{\text {th }}$ & $90^{\text {th }}$ \\
\hline $\mathrm{P}_{\text {thresh }}=10 \%$ & $7.9 \times 10^{-5}$ & $4.9 \times 10^{-4}$ & $2.8 \times 10^{-3}$ & $1.8 \times 10^{-2}$ & $3.6 \times 10^{-2}$ \\
$\mathrm{P}_{\text {thresh }}=25 \%$ & $7.9 \times 10^{-5}$ & $4.7 \times 10^{-4}$ & $2.4 \times 10^{-3}$ & $1.5 \times 10^{-2}$ & $3.3 \times 10^{-2}$ \\
$\mathrm{P}_{\text {thresh }}=50 \%$ & $7.9 \times 10^{-5}$ & $3.9 \times 10^{-4}$ & $2.4 \times 10^{-3}$ & $1.5 \times 10^{-2}$ & $3.3 \times 10^{-2}$ \\
$\mathrm{P}_{\text {thresh }}=75 \%$ & $7.8 \times 10^{-5}$ & $3.1 \times 10^{-4}$ & $9.4 \times 10^{-4}$ & $3.1 \times 10^{-3}$ & $5.0 \times 10^{-3}$ \\
$\mathrm{P}_{\text {thresh }}=90 \%$ & $3.5 \times 10^{-17}$ & $1.6 \times 10^{-13}$ & $3.7 \times 10^{-7}$ & $2.1 \times 10^{-4}$ & $5.9 \times 10^{-4}$ \\
\hline
\end{tabular}

(i.e. $n_{V B P, \text { pixel } x, y} / n_{V B P}$ total $)$. Following the typical roofing stocks of Spence et al. (2005) for the European area, the resulting probabilities were then multiplied by the probabilities of occurrence of their respective roof classes in either Median or Strong roofing stocks (Table 4) and summed into a final composite probability of roof perforation.

Figure 9, Table 5 and Table 6 summarize the impact of VBPs on the built environment. Figure 9 can be read as a box and whisker plot, in which black dots indicate raw composite probabilities of perforation of individual buildings $(n=1093)$ calculated for a hazard occurring at a given probability of occurrence (x axis). The resulting distributions are displayed as the median (red line), the $25^{t h}-75^{\text {th }}$ percentiles range (blue area) and the $10^{\text {th }}-90^{\text {th }}$ percentiles range (orange area). For instance, considering i) a probability of occurrence of the hazard of $50 \%$ and ii) a median roofing stock, the top of the orange box in Figure 9 (i.e. the $90^{t h}$ percentile) shows that $90 \%$ of the buildings have a $\leq 3.3 \times 10^{-2} \%$ probability of roof perforation, which also means that the remaining $10 \%$ have a $>3.3 \times 10^{-2} \%$ probability of perforation. Tables 5 and 6 report the same type of information. For i) a probability of occurrence of the hazard of $50 \%$ and ii) a strong roofing stock, the $50^{\text {th }}$ percentile in Table 6 shows that $50 \%$ of the buildings have probabilities of roof perforation either lower or higher than $6.7 \times 10^{-4 \%}$. Results indicate that probabilities of roof perforation are lower than $0.1 \%$ for all roofing stocks and probabilities of occurrence of the hazard. 
Table 6: Summary of the impact considering a typical Strong roofing stock (Spence et al., 2005). Values represent the probability of roof collapse calculated at given percentiles on the distributions shown in Fig. 9. $\mathrm{P}_{\text {thresh }}$ represents the probability threshold used to compile probabilistic energy maps (Fig. 6C-D).

\begin{tabular}{llllll}
\hline & \multicolumn{4}{l}{ Probability of roof perforation $(\%)-$ Strong roofing stock } \\
\hline Percentile: & $10^{\text {th }}$ & $25^{\text {th }}$ & $50^{\text {th }}$ & $75^{\text {th }}$ & $90^{\text {th }}$ \\
\hline $\mathrm{P}_{\text {thresh }}=10 \%$ & $2.2 \times 10^{-5}$ & $3.5 \times 10^{-4}$ & $1.8 \times 10^{-3}$ & $7.5 \times 10^{-3}$ & $1.3 \times 10^{-2}$ \\
$\mathrm{P}_{\text {thresh }}=25 \%$ & $2.2 \times 10^{-5}$ & $2.0 \times 10^{-4}$ & $9.0 \times 10^{-4}$ & $4.2 \times 10^{-3}$ & $9.2 \times 10^{-3}$ \\
$\mathrm{P}_{\text {thresh }}=50 \%$ & $2.2 \times 10^{-5}$ & $1.4 \times 10^{-4}$ & $6.7 \times 10^{-4}$ & $4.2 \times 10^{-3}$ & $9.1 \times 10^{-3}$ \\
$\mathrm{P}_{\text {thresh }}=75 \%$ & $2.1 \times 10^{-5}$ & $5.2 \times 10^{-5}$ & $1.7 \times 10^{-4}$ & $3.9 \times 10^{-4}$ & $8.4 \times 10^{-4}$ \\
$\mathrm{P}_{\text {thresh }}=90 \%$ & $2.8 \times 10^{-18}$ & $1.3 \times 10^{-14}$ & $2.9 \times 10^{-8}$ & $4.3 \times 10^{-5}$ & $1.1 \times 10^{-4}$ \\
\hline
\end{tabular}

\section{Discussion}

We introduce a new model called The Great Balls of Fire designed for the probabilistic analysis of VBP impacts. The model relies on the identification of probabilistic eruption scenarios described by distributions of selected input parameters, namely i) initial ejection velocities, ii) size distribution and iii) densities of VBPs. Sets of post-processing functions are also provided to compile probabilities of VBP impacts exceeding hazardous thresholds of kinetic energies. Probabilities can be expressed on a pixel-based approach, suitable for hazard and pre-event impact assessments, or on zones of interests (either concentric circles around or radial sector around the vent), suitable for hazard zoning purposes.

\subsection{Probabilistic hazard assessment for VBPs}

Hazard assessments for VBPs published in the literature follow two main approaches. Some authors used the Eject! model to estimate probability density functions of impact distances based on ESPs inferred from observed VBPs (e.g. Sandri et al., 2014). In contrast, other authors associate hazard zones based on deterministic eruption scenarios with their respective probabilities of occurrence (e.g. Alatorre-Ibargüengoitia et al., 2006, 2012). Here, we aim at providing a fully probabilistic assessment for VBP impacts as a basis to produce long-term multi-hazard assessments based on Bayesian event trees (e.g. Marzocchi et al., 2008; Selva et al., 2010; Sandri et al., 2014; Sheldrake, 2014; Thompson et al., 2015). The probabilistic approach adopted here is associated with a dependency on both the number of simulated VBPs and on the size of the zones of interest defined to average VBP impacts. 
This aspect should be investigated on a case-per-case basis, with the aim of finding the best compromise between computation time and output accuracy. As an example at La Fossa, Figure 3 shows minimum discrepancies of mean and standard deviation values of probabilities from $10^{6}$ simulated particles, which results in valid results up to a distance 3,000 $\mathrm{m}$ away from the vent, shown as the dashed circle on Figure 6. In contrast, $10^{7}$ particles increase the confidence radius to about $3,500 \mathrm{~m}$, but results in both calculation and post-processing times multiplied by a factor 10 .

\subsection{Probabilistic eruption scenarios for VBPs}

In probabilistic hazard assessments, eruption scenarios are typically expressed as distributions of the most critical ESPs for the modelled phenomenon (e.g. earthquake source parameters for seismic and tsunami hazard assessments, Geist and Parsons, 2006; volume for landslide hazard assessments, Guzzetti et al., 2005; thickness and volumes for lava flows, Connor et al., 2012). Alatorre-Ibargüengoitia et al. (2006) identified the total kinetic energy of Vulcanian explosions as the relevant ESP for defining eruption scenarios for VBPs, which can practically only be relevant when i) the ballistic model is coupled with a conduit model (e.g. Alatorre-Ibargüengoitia et al., 2012) and ii) when deterministic eruption scenarios are used.

Eruption scenarios as defined with our method differ from those presented by Alatorre-Ibargüengoitia et al. (2012) for Popocatepetl on two main points. Firstly, in our method, ESPs are those identified by Mastin (2001) stochastically sampled on a Gaussian distribution (Table 3). Secondly, the hazard zones resulting from the hazard assessment of Alatorre-Ibargüengoitia et al. (2012) for Popocatepetl are a direct consequence of the eruption scenarios, and, for instance, the high-hazard zone is defined as the typical VBP range resulting from the most likely and least intense type of activity. This deterministic approach, although complementary to the probabilistic approach when the probability of a future eruption tends to 1 (Marzocchi et al., 2008), is of limited information for long-term planning and risk reduction strategies. As an example, the cone of Popocatepetl is mostly deserted within a radius of a few kilometres around the vent, and the purpose of a risk assessment for VBPs is mainly the delimitation of exclusion zones. In contrast, urban areas are found within a radius of $1 \mathrm{~km}$ around La Fossa and probabilistic approaches become a necessity to estimate the likelihood of occurrence of VBPs impacts as a first step towards the development and implementation of pro-active risk mitigation strategies. 


\subsection{Eruptive scenarios at La Fossa}

We developed a scenario for typical long-lasting Vulcanian eruptions at La Fossa based on the inversion of field observations (Fig. 2) and the comparison with published literature (e.g. Alatorre-Ibargüengoitia et al., 2012; Fitzgerald et al., 2014; Tsunematsu et al., 2014). Using the caprock assumption, VBPs of different sizes have equal probabilities to be launched in the velocity range expressed in Table 3. Ejection velocities reported in the literature range from 30 to $400 \mathrm{~m} \mathrm{~s}^{-1}$ (Mastin, 1995; Fitzgerald et al., 2014; Alatorre-Ibargüengoitia et al., 2012). In the case of La Fossa, the distribution was assumed Gaussian with values of mean and standard deviations of 100 and $50 \mathrm{~m} \mathrm{~s}^{-1}$, respectively, which implies that $95 \%$ of the VBP's will result in ejection velocities comprised between $>0$ and $200 \mathrm{~m} \mathrm{~s}^{-1}$, respectively. We argue that this range is justifiable because i) it covers the majority of ejection velocities identified for other volcanoes while discarding sub- or supersonic velocities that are unlikely at La Fossa and ii) agrees with ranges obtained through inversion of field data (Fig. 2). The size distribution of VBPs is described here by a Gaussian distribution in $\phi$ units (i.e. a log-normal distribution is metres). Although Weibull distributions or fractal dimensions are thought to better represent the physical fragmentation process (Brown and Wohletz, 1995; Kaminski and Jaupart, 1998; Turcotte, 1986), the assumption of a Gaussian shape is frequent in numerical modelling (e.g. Macedonio et al., 1988; Fitzgerald et al., 2014).

At La Fossa, the 1888-1890 eruption is characterized by at least three populations of VBPs characterized by different densities (Table 2). Our approach accounts for three different populations of densities, weighing the number of simulated VBP according to proportions of occurrence of each VBP type observed in the field. However, observations of Mercalli and Silvestri (1891) suggest that each VBP type was produced at different stages of the two-year-long Vulcanian cycle. Outcomes of our probabilistic hazard assessment do not capture the evolution of VBP type through time and should be viewed as a time-integrated hazard over the duration of a Vulcanian cycle.

\subsection{VBP hazard for Vulcano}

At La Fossa, Figure $6 \mathrm{~A}-\mathrm{B}$ shows a maximum probability of occurrence of $1 \%$ for an energy threshold of $100 \mathrm{~J}$. The minimum probability of $10^{-4}$ (Fig. 6) is constrained by the number of simulated particles and occurs when a given pixel was impacted by one single VBP. Such low probabilities result from the reasons discussed in section 6.1, i.e. the consideration of a hazard 
occurring on discrete points rather than a continuous blanketing resulting, for instance, from tephra fallout. In this latter case, a probability of $100 \%$ of a threshold of tephra accumulation occurs when this threshold was exceeded at a given pixel at each single run of the model. In contrast, an hypothetical probability of $100 \%$ to exceed a given energy threshold when considering VBPs would imply that all simulated particles exceeded the probability threshold and fell into a single pixel. As a result, although Biass et al. (submitted) show an average probability $15-30 \%$ to exceed critical accumulations of tephra for the collapse of the weakest roofs in the Porto area, probabilities of occurrences of VBPs with critical energies for the built environment are comprised between $10^{-3}-10^{-2 \%}$. When probability maps are converted to energy maps (Fig. 6), our results show a probability of occurrence of high energies that increases with distance from the vent. For the case of a steamblast eruption, Dellino et al. (2011) suggest a zone extending $200 \mathrm{~m}$ from the vent characterized by a maximum energy of $10^{6} \mathrm{~J}$ based on field observations. Our probabilistic approach suggests that in the case of a Vulcanian eruption, such an energy has low probabilities of occurrence within 2,500 m around the vent.

La Fossa is a $391 m$ high cone surrounded in the south and west by a caldera rim rising from 250 to $400 \mathrm{~m}$ above sea level. From the DEM, the height of the actual crater was estimated at $\sim 220 \mathrm{~m}$, and GBF simulations were performed with a $200 m$-high region of reduced drag (Table 3). As a result, although a careful observation of the distribution of probabilities on Figure 6 reveals a slight increase of impacts on the caldera rim, our hazard assessment shows that the island does not host significant topographic barriers to shelter from VBPs, leaving only the southernmost part of the island with a virtually null probability of impact. On the other hand, simulations performed with a null region of reduced drag does not significantly change the final probabilistic hazard assessment.

Biass et al. (submitted) presents a study of wind patterns for the period 1980-2010 inferred from the ECMWF ERA- Interim database (Dee et al., 2011), which reveals a $\sim 70 \%$ probability of wind directed towards SE at sea level, with associated velocities rarely higher than $20 \mathrm{~m} \mathrm{~s}^{-1}$. To test the influence of wind on the final probabilistic hazard assessment, simulations were run with a mean wind with a constant velocity of $20 \mathrm{~m} \mathrm{~s}^{-1}$ and a constant wind direction (i.e. provenance $+180^{\circ}$ ) of $135^{\circ}$. Results show that the final probabilities are not significantly affected by wind conditions. This is due on one side to the fact that smaller particles will be more influenced 
by wind forces, which will necessarily fall relatively close to the vent due to the caprock assumption. In this case the large number of particles falling in proximal area is the dominant influence on the final probability values. On the other side, only a limited number of large particles will impact more distal areas, but since wind has little effect on them, their additional displacement is not sufficient to affect the final probability values.

\subsection{Pre-event impact assessment}

The probabilistic hazard assessment was combined with an estimation of the vulnerability of the built environment to assess potential impacts associated with VBPs. Here, the vulnerability regards the potential strength of a building to resist roof perforation resulting from a dynamic impact, which regards the risk on the built environment as a potential loss of life (e.g. Spence et al., 2005; Jenkins et al., 2014) rather than expressing the loss of economical value (e.g. Blong, 2003a). Following Biass et al. (submitted), the vulnerability of the built environment was based on the typical roofing stocks of Spence et al. (2005) for the European area, extrapolated to dynamic impacts following two main assumptions.

Firstly, the limited observations of damages related to VBPs impacts does not allow to develop robust vulnerability curves. In natural hazards, the closest analogous phenomena associated with impacts at high kinetic energies include hail storms and rockfalls (e.g. Andrews and Blong, 1997; Hohl et al., 2002; Mavrouli and Corominas, 2010a,b; Agliardi et al., 2009). Resulting fragility curves can take various shapes such as sigmoid (e.g. Agliardi et al., 2009) and logistic (e.g. Hohl et al., 2002) shapes. Here, in the absence of more detailed information, we follow the approach undertaken for tephra fallout (e.g. Spence et al., 2005; Pomonis et al., 1999; Jenkins et al., 2014) using a lognormal distribution and a fixed geometric standard deviation of 0.2. Secondly, published post-event impact assessments report VBP impacts associated with variable energy thresholds (e.g. Pomonis et al., 1999; Blong, 2003b, 1984). Here, we estimated mean energy thresholds for the built environment on Vulcano by comparing observed impacts with typology of buildings resulting from our field survey (Biass et al., submitted). As a result, two end-members of vulnerability to VBPs were identified comprising tile roofs on the weakest spectrum and reinforced concrete roofs on the strongest. Figure 4 reflects this bipolarity due to critical energy thresholds varying by orders of magnitude between the two families of roofs identified in Vulcano (i.e. tiles and reinforced concrete; Table 4). 
In terms of cascading effects between volcanic hazards, the relationship between VBPs and tephra is ambiguous. On one hand, tephra can act as a blanket absorbing energy from a VBP and thus reduce it propensity to perforation from a dynamic impact. On another hand, VBPs can increase the static load already caused by tephra layers and contribute to roof collapse. These complex vulnerability patterns occurring in the context of multihazards risk assessments were already discussed by Zuccaro et al. (2008) and underline the complex task of combining fragility curves for different natures of hazards (i.e. static load vs. dynamic impact) potentially simultaneously affecting exposed elements.

\section{Conclusion}

A new approach for the hazard assessment related to the ejection of VBPs is introduced, which quantifies the probabilities of occurrence of VBP impacts exceeding hazardous thresholds of kinetic energy. This approach, in line with recent efforts to quantify volcanic hazards in terms of probabilities, relies on a new ballistic model called The Great Balls of Fire, with the main features being:

- The definition of ESPs in terms of probability distributions;

- A variable drag coefficient;

- A fast computation time;

- The possibility to work on single CPUs or clusters of computers;

- Platform independent.

The model is distributed in open-source and made available on VHub. It was validated using field observations of VBPs associated from eruptions of La Fossa volcano. Additionally, sets of Matlab functions are provided to post process the model output into probabilistic hazard assessments for VBPs, resulting in a format useful for the integration in various GIS environments. Both the model and the post-processing functions are available as Online Resources along with the user manual.

A generic Vulcanian eruption scenario was identified for La Fossa based on the stratigraphy of the last 1000 years. Results show that the settlements of Lentia and Porto are the most likely to be impacted by VBP, whereas 
Vulcanello and Piano are relatively safer (Fig. 4). In addition, the vulnerability of the built environment was assessed by extrapolating the generic vulnerability curves for Europe of Spence et al. (2005) for tephra fallout to VBPs based on a review of critical energy thresholds found in the literature along with a field survey of the built environment on Vulcano. Both hazard and vulnerability aspects were then combined to produce a first-order preevent impact assessment in terms of potential number of affected buildings. Results show that although no building has a probability of roof perforation higher than $10^{-2} \%$, the occurrence of a VBP impact is likely to result in high reparation costs.

\section{Acknowledgements}

We are grateful to C. Frischknecht, H. Monnard, A. Cuomo and I. Manzella for providing the results of the building survey, to A. Galderisi for the building shapefiles, to L. Chevalley et C. Haenggeli for their help in the characterization of the built environment, to G. Bagheri, S. Jenkins and L. Pioli for the insightful comments and to J.L. Lewis for a great name. Computations were performed at University of Geneva on the Baobab cluster. S. Biass is supported by a SNF grant (\#200021-129997).

Agliardi, F., Crosta, G. B., Frattini, P., Jul. 2009. Integrating rockfall risk assessment and countermeasure design by 3D modelling techniques. Nat. Hazards Earth Syst. Sci. 9 (4), 1059-1073.

URL http://www.nat-hazards-earth-syst-sci.net/9/1059/2009/ http://www . nat-hazards-earth-syst-sci.net/9/1059/2009/nhess-9-1059-2009.pdf

Alatorre-Ibargüengoitia, M., Delgado-Granados, H., Dingwell, D., Nov. 2012. Hazard map for volcanic ballistic impacts at Popocatépetl volcano (Mexico). Bull Volcanol 74 (9), 2155-2169.

Alatorre-Ibargüengoitia, M., Scheu, B., Dingwell, D., Delgado-Granados, H., Taddeucci, J., May 2010. Energy consumption by magmatic fragmentation and pyroclast ejection during Vulcanian eruptions. Earth and Planetary Science Letters 291 (14), 60-69.

Alatorre-Ibargüengoitia, M. A., Delgado-Granados, H., Jun. 2006. Experimental determination of drag coefficient for volcanic materials: Calibration and application of a model to Popocatépetl volcano (Mexico) ballistic 
projectiles. Geophysical Research Letters 33 (11), L11302.

URL http://dx.doi.org/10.1029/2006GL026195

Alatorre-Ibargüengoitia, M. A., Delgado-Granados, H., Farraz-Montes, I. A., Jan. 2006. Hazard zoning for ballistic impact during volcanic explosions at Volcán de Fuego de Colima (México). Geological Society of America Special Papers 402, 209-216. URL http://specialpapers .gsapubs .org/content/402/209. abstract

Andrews, K., Blong, R., 1997. March 1990 Hailstorm Damage in Sydney, Australia. Natural Hazards 16 (2-3), 113-125.

URL http://dx.doi.org/10.1023/A\%3A1007913508192

Arrighi, S., Tanguy, J.-C., Rosi, M., Apr. 2006. Eruptions of the last 2200 years at Vulcano and Vulcanello (Aeolian Islands, Italy) dated by highaccuracy archeomagnetism. Physics of the Earth and Planetary Interiors 159 (34), 225-233.

Bianchi, L., 2007. Leruzione 1888-1890 di Vulcano (Isole Eolie):Analisi stratigrafica, fisica e composizionale dei prodotti. Unpublished msc thesis, Università di Pisa.

Biass, S., Scaini, C., Bonadonna, C., Folch, A., Smith, K., Höskuldsson, A., Aug. 2014. A multi-scale risk assessment for tephra fallout and airborne concentration from multiple Icelandic volcanoes - Part 1: Hazard assessment. Nat. Hazards Earth Syst. Sci. 14 (8), 2265-2287. URL http://www.nat-hazards-earth-syst-sci.net/14/2265/2014/ http://www . nat-hazards-earth-syst-sci .net/14/2265/2014/nhess-14-2265-2014.pdf

Blong, R., 2003a. A New Damage Index. Nat. Hazards. 30, 1-23.

Blong, R., 2003b. Building damage in Rabaul, Papua New Guinea, 1994. Bulletin of Volcanology 65 (1), 43-54.

Blong, R. J., 1984. Volcanic hazards. A sourcebook on the effects of eruptions. Academic Press, Orlando.

Bonadonna, C., 2006. Probabilistic modelling of tephra dispersion. Statistics in volcanology, 243-259. 
Bonadonna, C., Biass, S., Manzella, I., Galderisi, A., Ceudech, A., Ferrara, F., Delmonaco, G., Menoni, S., Minucci, G., Belvaux, M., Manceau, J., Montfort-Climent, D., Sabourault, P., Foerster, E., 2011. Application of an integrated vulnerability conceputal approachm Del. 5.3.3: Development of the Integrated Approach on the Vulcano case study. Tech. Rep. 212045, Ensure project. Tech. rep.

Brown, W. K., Wohletz, K. H., 1995. Derivation of the Weibull distribution based on physical principles and its connection to the RosinRammler and lognormal distributions. Journal of Applied Physics 78 (4).

Connor, L., Connor, C., Meliksetian, K., Savov, I., 2012. Probabilistic approach to modeling lava flow inundation: a lava flow hazard assessment for a nuclear facility in Armenia. J Appl. Volcanol. 1 (1), 1-19.

De Astis, G., Lucchi, F., Dellino, P., La Volpe, L., Tranne, C. A., Frezzotti, M. L., Peccerillo, A., Jan. 2013. Chapter 11 Geology, volcanic history and petrology of Vulcano (central Aeolian archipelago). Geological Society, London, Memoirs 37 (1), 281-349.

URL http://mem. lyellcollection.org/content/37/1/281. abstract

De Astis, G., Volpe, L., Peccerillo, A., Civetta, L., Jan. 1997. Volcanological and petrological evolution of Vulcano island (Aeolian Arc, southern Tyrrhenian Sea). Journal of Geophysical Research: Solid Earth 102 (B4), 8021-8050.

De Fiore, O., 1922. Vulcano (Isole Eolie). In: Friedlaender, I. (Ed.), Revisita Vulcanologica (Suppl. 3). pp. 1-393.

De' Michieli Vitturi, M., Neri, A., Esposti Ongaro, T., Lo Savio, S., Boschi, E., Aug. 2010. Lagrangian modeling of large volcanic particles: Application to Vulcanian explosions. Journal of Geophysical Research: Solid Earth 115 (B8), B08206.

URL http://dx.doi.org/10.1029/2009JB007111

Dee, D. P., Uppala, S. M., Simmons, A. J., Berrisford, P., Poli, P., Kobayashi, S., Andrae, U., Balmaseda, M. A., Balsamo, G., Bauer, P., Bechtold, P., Beljaars, A. C. M., van de Berg, L., Bidlot, J., Bormann, N., Delsol, C., Dragani, R., Fuentes, M., Geer, A. J., Haimberger, L., Healy, S. B., Hersbach, H., Hólm, E. V., Isaksen, L., Kå llberg, P., Köhler, M., Matricardi, 
M., McNally, A. P., Monge-Sanz, B. M., Morcrette, J.-J., Park, B.-K., Peubey, C., de Rosnay, P., Tavolato, C., Thépaut, J.-N., Vitart, F., Apr. 2011. The ERA-Interim reanalysis: configuration and performance of the data assimilation system. Quarterly Journal of the Royal Meteorological Society 137 (656), 553-597. URL http://dx.doi.org/10.1002/qj. 828

Dellino, P., Astis, G., Volpe, L., Mele, D., Sulpizio, R., Jan. 2011. Quantitative hazard assessment of phreatomagmatic eruptions at Vulcano (Aeolian Islands, Southern Italy) as obtained by combining stratigraphy, event statistics and physical modelling. Journal of Volcanology and Geothermal Research 201 (14), 364-384.

Dellino, P., La Volpe, L., 1997. Stratigrafia, dinamiche eruttive e deposizionali, scenario eruttivo e valutazioni di pericolosità a La Fossa di Vulcano. Tech. rep., CNR-Gruppo Nazionale per la Vulcanologia, Volume speciale Vulcano-Progetto triennale 19931995.

Di Traglia, F., Apr. 2011. The last 1000 years of eruptive activity at the Fossa Cone (Island of Vulcano, Southern Italy). Ph.D. thesis.

Di Traglia, F., Pistolesi, M., Rosi, M., Bonadonna, C., Fusillo, R., Roverato, M., Jul. 2013. Growth and erosion: The volcanic geology and morphological evolution of La Fossa (Island of Vulcano, Southern Italy) in the last 1000 years. Geomorphology 194 (0), 94-107.

URL http://www.sciencedirect.com/science/article/pii/S0169555X13002249

Fagents, S. A., Wilson, L., May 1993. Explosive volcanic eruptionsVII. The ranges of pyroclasts ejected in transient volcanic explosions. Geophysical Journal International 113 (2), 359-370. URL http://gji.oxfordjournals.org/content/113/2/359. abstract

Fitzgerald, R., Tsunematsu, K., Kennedy, B., Breard, E., Lube, G., Wilson, T., Jolly, A., Pawson, J., Rosenberg, M., Cronin, S., May 2014. The application of a calibrated 3D ballistic trajectory model to ballistic hazard assessments at Upper Te Maari, Tongariro. Journal of Volcanology and Geothermal Research.

URL http://www.sciencedirect.com/science/article/pii/S0377027314001164

Fournier d'Albe, E. M., 1979. Objectives of volcanic monitoring and prediction. J Geol Soc Lond 136, 321-326. 
Frazzetta, G., Gillot, P. Y., Volpe, L., Sheridan, M. F., 1984. Volcanic hazards at Fossa of Vulcano: Data from the last 6,000 years. Bulletin Volcanologique 47 (1), 105-124.

URL http://dx.doi.org/10.1007/BF01960543

Frazzetta, G., La Volpe, L., Sheridan, M. F., Sep. 1983. Evolution of the Fossa Cone, Vulcano. Journal of Volcanology and Geothermal Research 17 (1-4), 329-360.

URL http://www.sciencedirect.com/science/article/pii/0377027383900756

Fudali, R. F., Melson, W. G., 1971. Ejecta velocities, magma chamber pressure and kinetic energy associated with the 1968 eruption of arenal volcano. Bulletin Volcanologique 35 (2), 383-401. URL http://dx.doi.org/10.1007/BF02596963

Galderisi, A., Bonadonna, C., Delmonaco, G., Ferrara, F., Menoni, S., Ceudech, A., Biass, S., Frischknecht, C., Manzella, I., Minucci, G., Gregg, C., 2013. Vulnerability Assessment and Risk Mitigation: The Case of Vulcano Island, Italy. In: Margottini, C., Canuti, P., Sassa, K. (Eds.), Landslide Science and Practice SE - 8. Springer Berlin Heidelberg, pp. 55-64. URL http://dx.doi .org/10.1007/978-3-642-31313-4_8

Geist, E. L., Parsons, T., 2006. Probabilistic analysis of tsunami hazards. Natural Hazards 37 (3), 277-314.

Gioncada, A., Mazzuoli, R., Bisson, M., Pareschi, M., Apr. 2003. Petrology of volcanic products younger than $42 \mathrm{ka}$ on the LipariVulcano complex (Aeolian Islands, Italy): an example of volcanism controlled by tectonics. Journal of Volcanology and Geothermal Research 122 (3-4), 191-220. URL http://www.sciencedirect.com/science/article/pii/S0377027302005024

Gonzalez, F. I., Geist, E. L., Jaffe, B., Kanoglu, U., Mofjeld, H., Synolakis, C. E., Titov, V. V., Arcas, D., Bellomo, D., Carlton, D., Horning, T., Johnson, J., Newman, J., Parsons, T., Peters, R., Peterson, C., Priest, G., Venturato, A., Weber, J., Wong, F., Yalciner, A., 2009. Probabilistic tsunami hazard assessment at Seaside, Oregon, for near- and far-field seismic sources. Journal of Geophysical Research-Oceans 114.

Gurioli, L., Zanella, E., Gioncada, A., Sbrana, A., 2012. The historic magmatic-hydrothermal eruption of the Breccia di Commenda, Vulcano, Italy. Bulletin of Volcanology, 1-20. 
Guzzetti, F., Reichenbach, P., Cardinali, M., Galli, M., Ardizzone, F., Dec. 2005. Probabilistic landslide hazard assessment at the basin scale. Geomorphology 72 (1-4), 272-299.

URL http://www.sciencedirect.com/science/article/pii/S0169555X05001911

Heneka, P., Hofherr, T., 2011. Probabilistic winter storm risk assessment for residential buildings in Germany. Natural Hazards 56 (3), 815-831. URL http://www.mendeley.com/catalog/probabilistic-winter-storm-risk-assessment-

Hohl, R., Schiesser, H.-H., Aller, D., Aug. 2002. Hailfall: the relationship between radar-derived hail kinetic energy and hail damage to buildings. Atmospheric Research 63 (3-4), 177-207. URL http://www.sciencedirect.com/science/article/pii/S0169809502000595

ISTAT, 2005. Progetto Census 2000 - Aggiornamento delle basi territoriali, Descrizione dei dati. Tech. rep.

Jenkins, S., Magill, C., McAneney, J., Blong, R., 2012. Regional ash fall hazard I: a probabilistic assessment methodology. Bulletin of Volcanology, $1-14$.

Jenkins, S., Spence, R., Fonseca, J., Solidum, R., Wilson, T., Apr. 2014. Volcanic risk assessment: Quantifying physical vulnerability in the built environment. Journal of Volcanology and Geothermal Research 276, 105-120.

URL http://www.sciencedirect.com/science/article/pii/S0377027314000729

Kaminski, E., Jaupart, C., Dec. 1998. The size distribution of pyroclasts and the fragmentation sequence in explosive volcanic eruptions. Journal of Geophysical Research: Solid Earth 103 (B12), 29759-29779.

URL http://dx.doi.org/10.1029/98JB02795

Keller, J., 1980. The island of Vulcano. Rendiconti Società Italiana Mineralogia e Petrologia 36, 369-414.

Macedonio, G., Pareschi, M. T., Santacroce, R., Dec. 1988. A numerical simulation of the Plinian Fall Phase of 79 A.D. eruption of Vesuvius. Journal of Geophysical Research: Solid Earth 93 (B12), 14817-14827. URL http://dx.doi.org/10.1029/JB093iB12p14817 
Marzocchi, W., Sandri, L., Selva, J., 2008. BET_EF: a probabilistic tool for long- and short-term eruption forecasting. Bulletin of Volcanology 70 (5), 623-632.

Mastin, L. G., 1995. Thermodynamics of gas and steam-blast eruptions. Bulletin of Volcanology 57 (2), 85-98.

URL http://dx.doi.org/10.1007/BF00301399

Mastin, L. G., 2001. A simple calculator of ballistic trajectories for blocks ejected during volcanic eruptions. Tech. rep., U.S. Geological Survey OpenFile Report 01-45.

URL http://pubs .usgs.gov/of/2001/0045/

Mavrouli, O., Corominas, J., Oct. 2010a. Rockfall vulnerability assessment for reinforced concrete buildings. Nat. Hazards Earth Syst. Sci. 10 (10), 2055-2066.

URL http://www.nat-hazards-earth-syst-sci.net/10/2055/2010/ http: //www . nat-hazards-earth-syst-sci.net/10/2055/2010/nhess-10-2055-2010.pdf

Mavrouli, O., Corominas, J., 2010b. Vulnerability of simple reinforced concrete buildings to damage by rockfalls. Landslides 7 (2), 169-180.

URL http://dx.doi.org/10.1007/s10346-010-0200-5

Mendoza-Rosas, A. T., la Cruz-Reyna, S., 2008. A statistical method linking geological and historical eruption time series for volcanic hazard estimations: Applications to active polygenetic volcanoes. Journal of volcanology and geothermal research 176 (2), 277-290.

Mercalli, G., Silvestri, O., 1891. Le eruzioni dell'Isola di Vulcano incominciate il 3 agosto 1888 e terminate il 22 marzo 1890, relazione scientifica. Ann Ufficio Centrale Metereol Geodin Ital 10, 1-213.

Minakami, T., 1942. 5. On the Distribution of Volcanic Ejecta. (Part 1) The Distributions of Volcanic Bombs ejected by the Recent Explosion of Asama. Bulletin of the Earthquake Research Institute 20 (65-69).

Petrazzuoli, S., Zuccaro, G., May 2004. Structural resistance of reinforced concrete buildings under pyroclastic flows: a study of the Vesuvian area. Journal of Volcanology and Geothermal Research 133 (1-4), 353-367. URL http://www. sciencedirect.com/science/article/pii/S0377027303004074 
Pistolesi, M., Donne, D., Pioli, L., Rosi, M., Ripepe, M., Jan. 2011. The 15 March 2007 explosive crisis at Stromboli volcano, Italy: Assessing physical parameters through a multidisciplinary approach. Journal of Geophysical Research 116.

Pomonis, A., Spence, R., Baxter, P., 1999. Risk assessment of residential buildings for an eruption of Furnas Volcano, Sao Miguel, the Azores. Journal of volcanology and geothermal research 92 (1-2), 107-131.

Rosi, M., Pistolesi, M., Bertagnini, A., Landi, P., Pompilio, M., Di Roberto, A., Jan. 2013. Stromboli volcano, Aeolian Islands (Italy): present eruptive activity and hazards. Geological Society, London, Memoirs 37 (1), 473490. URL http://mem.lyellcollection.org/content/37/1/473.abstract

Sandri, L., Thouret, J.-C., Constantinescu, R., Biass, S., Tonini, R., 2014. Long-term multi-hazard assessment for El Misti volcano (Peru). Bulletin of Volcanology 76 (2), 1-26.

URL http://dx.doi .org/10.1007/s00445-013-0771-9

Self, S., Wilson, L., Nairn, I., 1979. Vulcanian eruption mechanisms. Nature $277,440-443$.

Selva, J., Costa, A., Marzocchi, W., Sandri, L., 2010. BET_VH: exploring the influence of natural uncertainties on long-term hazard from tephra fallout at Campi Flegrei (Italy). Bulletin of Volcanology 72 (6), 717-733.

Sheldrake, T., Aug. 2014. Long-term forecasting of eruption hazards: a hierarchical approach to merge analogous eruptive histories. Journal of Volcanology and Geothermal Research.

URL http://www.sciencedirect.com/science/article/pii/S0377027314002613

Spence, R. J. S., Kelman, I., Baxter, P. J., Zuccaro, G., Petrazzuoli, S., 2005. Residential building and occupant vulnerability to tephra fall. Natural Hazards and Earth System Sciences 5 (4), 477-494.

Steinberg, G. S., Lorenz, V., 1983. External ballistic of volcanic explosions. Bulletin Volcanologique 46 (4), 333-348. URL http://dx.doi.org/10.1007/BF02597769 
Thompson, M., Lindsay, J., Sandri, L., Biass, S., Bonadonna, C., Jolly, G., Marzocchi, W., 2015. Exploring the influence of vent location and eruption style on tephra fall hazard from the Okataina Volcanic Centre, New Zealand. Bulletin of Volcanology 77 (5), 1-23.

URL http://dx.doi .org/10.1007/s00445-015-0926-y

Tsunematsu, K., Mar. 2012. New numerical solutions for the description of volcanic particle dispersal. Tech. rep., University of Geneva.

URL https://archive-ouverte.unige.ch/unige: 26675

Tsunematsu, K., Chopard, B., Falcone, J.-L., Bonadonna, C., Feb. 2014. A numerical model of ballistic transport with collisions in a volcanic setting. Computers \& Geosciences 63, 62-69.

URL http://www.sciencedirect.com/science/article/pii/S009830041300280X

Turcotte, D. L., Feb. 1986. Fractals and fragmentation. Journal of Geophysical Research: Solid Earth 91 (B2), 1921-1926.

URL http://dx.doi.org/10.1029/JB091iB02p01921

Vanderkluysen, L., Harris, A., Kelfoun, K., Bonadonna, C., Ripepe, M., 2012. Bombs behaving badly: unexpected trajectories and cooling of volcanic projectiles. Bulletin of Volcanology 74 (8), 1849-1858.

URL http://dx.doi .org/10.1007/s00445-012-0635-8

Wilson, L., Dec. 1972. Explosive Volcanic Eruptions-II The Atmospheric Trajectories of Pyroclasts. Geophysical Journal International 30 (4), 381392.

URL http://gji.oxfordjournals.org/content/30/4/381.abstract

Wilson, L., Oct. 1980. Relationships between pressure, volatile content and ejecta velocity in three types of volcanic explosion. Journal of Volcanology and Geothermal Research 8 (2-4), 297-313.

URL http://www.sciencedirect.com/science/article/pii/0377027380901109

Wilson, T., Stewart, C., Sword-Daniels, V., 2011. Volcanic ash impacts on critical infrastructure. Phys. Chem. Earth Pt. A/B/C.

Zanella, E., Astis, G., Lanza, R., Apr. 2001. Palaeomagnetism of welded, pyroclastic-fall scoriae at Vulcano, Aeolian Archipelago. Journal of Volcanology and Geothermal Research 107 (13), 71-86. 
1119 Zuccaro, G., Cacace, F., Spence, R. J. S., Baxter, P. J., 2008. Impact of explo${ }_{1120}$ sive eruption scenarios at Vesuvius. Journal of volcanology and geothermal 1121 research $178(3), 416-453$.

1122 